\title{
Responses of summer phytoplankton biomass to changes in top-down forcing: Insights from comparative modelling
}

\author{
Maar Marie ${ }^{1,{ }^{*}}$, Butenschön Momme ${ }^{2,15}$, Daewel Ute ${ }^{3}$, Eggert Anja ${ }^{4}$, Fan Wei ${ }^{5}$, Hjøllo Solfrid S. ${ }_{4}^{6}$, \\ Hufnagl Marc ${ }^{7}$, Huret Martin ${ }^{8}$, Ji Rubao ${ }^{9}$, Lacroix Geneviève ${ }^{10}$, Peck Myron A. ${ }^{7}$, Radtke Hagen ${ }^{4}$, \\ Sailley Sévrine ${ }^{2}$, Sinerchia Matteo ${ }^{11}$, Skogen Morten D. ${ }^{6}$, Travers-Trolet Morgane ${ }^{12}$, \\ Troost Tineke A. ${ }^{13}$, Van De Wolfshaar Karen ${ }^{14}$
}

\footnotetext{
${ }_{1}^{1}$ Aarhus University, Department of Bioscience, 4000 Roskilde, Denmark

2 Plymouth Marine Laboratory, PL1 3DH Plymouth, UK

${ }^{3}$ Helmholtz Zentrum Geesthacht, Institute of Coastal Research, 21502 Geesthacht, Germany

${ }^{4}$ Leibniz Institute for Baltic Sea Research Warnemünde (IOW), 18119 Rostock, Germany

${ }^{5}$ Ocean College, Zhejiang University, Zhejiang 316021, China

${ }^{6}$ Inst. of Marine Research, N-5817 Bergen, Norway

${ }^{7}$ Institute of Hydrobiology and Fisheries Science, University of Hamburg, 22767 Hamburg, Germany

${ }^{8}$ IFREMER, Centre de Brest, STH/LBH, France

${ }^{9}$ Woods Hole Oceanographic Institution, Woods Hole, MA, 02543, United States

${ }^{10}$ Royal Belgian Institute of Natural Sciences, B-1200 Brussels, Belgium

${ }^{11}$ Institute for the Coastal Marine Environment-IAMC-CNR, 09170 Torregrande, Oristano, Italy

12 Ifremer, Centre Manche-Mer du Nord, 62321 Boulogne sur Mer, France

${ }^{13}$ Deltares, Boussinesqweg 1, 2629 HV Delft, The Netherlands

${ }_{14}^{14}$ Wageningen Marine Research, 1976 CP IJmuiden, The Netherlands

${ }^{15}$ Euro-Mediterranean Center on Climate Change (CMCC), 40127 Bologna, BO, Italy
}

${ }^{*}$ Corresponding author : Marie Maar, email address : $\underline{\text { mam@bios.au.dk }}$

\begin{abstract}
:
The present study describes the responses of summer phytoplankton biomass to changes in top-down forcing (expressed as zooplankton mortality) in three ecosystems (the North Sea, the Baltic Sea and the Nordic Seas) across different 3D ecosystem models. In each of the model set-ups, we applied the same changes in the magnitude of mortality $( \pm 20 \%)$ of the highest trophic zooplankton level $(Z 1)$. Model results showed overall dampened responses of phytoplankton relative to $Z 1$ biomass. Phytoplankton responses varied depending on the food web structure and trophic coupling represented in the models. Hence, a priori model assumptions were found to influence cascades and pathways in model estimates and, thus, become highly relevant when examining ecosystem pressures such as fishing and climate change. Especially, the different roles and parameterizations of additional zooplankton groups grazed by Z1, and their importance for the outcome, emphasized the need for better calibration data. Spatial variability was high within each model indicating that physics (hydrodynamics and temperature) and nutrient dynamics also play vital roles for ecosystem responses to top-down effects. In conclusion, the model comparison indicated that changes in top-down forcing in combination with the modelled foodweb structure affect summer phytoplankton biomass and, thereby, indirectly influence water quality of
\end{abstract}


the systems.

\section{Highlights}

- We applied the same change in top-down forcing to different 3D ecosystem models. Phytoplankton showed dampened responses compared to the highest trophic level. The roles of different zooplankton groups were important for the outcome. Environmental conditions affected the spatial variability of phytoplankton responses. Summer phytoplankton biomass was affected by changes in top-down forcing. A priori model assumptions should be considered when examining ecosystem pressures.

Keywords: Plankton functional types, Trophic cascades, Zooplankton mortality, Phytoplankton, Ensemble modelling 


\section{Introduction}

Overfishing, pollution or destruction of habitats combined with climate change impose pressures on marine food webs and it is challenging to predict how changes in the strength of these human-induced pressures will impact on the trophodynamic structure and function of ecosystems (Polis et al. 2000, Shurin et al. 2002, Heath et al. 2014). Top-down forcing is defined as the regulation of lower food-web components by an upper-level predator (Pace et al. 1999). Trophic cascades occur when pressures change the biomass of one trophic level and thereby the strength of the top-down forcing across more than one trophic link in a food web (Cury et al. 2003, Huse et al. 2012). The strong decline in populations of large top-predators observed in coastal and oceanic waters and corresponding changes in top-down forcing may have severe consequences for ecosystem function (Myers \& Worm 2003, Scheffer et al. 2005). Examples of top-down controlled systems are the Black Sea, the Eastern Scotian shelf off Canada and the Baltic Sea, where overfishing of the top predators directly affected the whole food web from planktivorous fish to primary producers and resulted in higher summer phytoplankton biomass (Frank et al. 2005, Casini et al. 2008, Möllmann et al. 2008, Llope et al. 2011).

High phytoplankton biomass is normally a sign of eutrophication caused by nutrient enrichment (bottom-up control) and summer phytoplankton biomass is used as an indicator of water quality in the HELCOM Baltic Sea Action Plan (HELCOM 2013). Top-down forced trophic cascades may thereby contribute to the eutrophication status and work against the goal to achieve a good ecological status in coastal and open waters according to the EU Water Framework Directive (2000/60/EC) and the EU Marine Strategy Framework Directive (2008/56/EC). On the other hand, it has been suggested that changes in fishing pressure on selected species could in turn decrease summer phytoplankton biomass and improve water clarity, as seen in lakes and some coastal ecosystems (Carpenter et al. 1985, Hansson et al. 1998, Lindegren et al. 2010, Petersen et al. 2017). Hence, knowledge on trophodynamics is 
important when formulating guidelines to sustainably manage fisheries as well as meet other management goals such as to maintain high water quality (Frank et al. 2007).

Responses to changes in top-down forcing often emerge as 'skipped-level-transmission', i.e. different directions of change between adjacent trophic levels (Casini et al. 2008, Heath et al. 2014). The strength of the response is often dampened by each trophic level due to various compensatory mechanisms that regulate internal food-web dynamics and structure (McCann et al. 1998a, Pace et al. 1999, Shurin et al. 2002, Andersen \& Pedersen 2010). The compensatory mechanisms include replacement of the affected species, regulation through density-dependent grazing pressure and loss of energy due to respiration, cannibalism and other types of mortality (Mccann et al. 1998b, Andersen \& Pedersen 2010). Trophic cascades are transitory and dynamic phenomenon and, hence, exhibit variation in their strength and duration both within and between systems, the latter due to ecosystem-specific differences in food web dynamics and structure (Cury et al. 2003).

Food web models have become an important tool in examining how reductions in specific predators or prey impact on other ecosystem components (Travers et al. 2007, Daewel et al. 2014, Peck et al. 2018). A general framework and theoretical description of the different types of food web responses that can be expected in relation to changes in trophodynamic controls was provided by Cury et al. (2003). Further, theoretical modelling has produced simple rules for how perturbations at upper trophic levels can affect the strength of potential trophic cascades within specific ecosystems (Mccann et al. 1998b, Leibold et al. 2004, Wollrab et al. 2012, Heath et al. 2014). Although these models take into account trophic complexity, they do not account for any local spatio-temporal variability of the ecosystem, which may affect predator-prey interactions and, hence, trophic cascades (Frank et al. 2007, Schulz et al. 2007, Travers \& Shin 2010). To fully and more realistically resolve the emergence of trophic responses in the plankton community, spatially- and temporally-explicit models are required which include both 
hydrodynamics and biogeochemical processes.

Ecosystem models of lower trophic levels depict nutrient cycling and dynamics of plankton functional types (PFTs) including primary producers and grazers with different life strategies and sizes (Blackford et al. 2004, Daewel et al. 2014). In these models, the zooplankton community ranges from unicellular fastgrowing microorganisms to multicellular meso- and macrozooplankton (e.g. copepods, krill) with longer generation times, but the community is often reduced to one or a few zoo-PFTs (Maar et al. 2011, Butenschön et al. 2016). Mesozooplankton (carnivorous or omnivorous) represents, in most cases, the highest trophic level and mortality on this group represents a closure term for nutrient and carbon fluxes. A background mortality (encompassing natural mortality, predation, cannibalism, diseases, etc.) is often applied as a linear, quadratic or saturation function assuming that e.g. higher densities of zooplankton will lead to more or less strong habitat limitation effects, might attract potential predators or will increase the likelihood of infections (Edwards \& Yool 2000, Fulton et al. 2003). Although different 3D ecosystem models may seem very similar, there can be important differences in their assumptions (e.g. food web structure, physiological rates, prey preferences, mortality terms) and underlying hydrodynamics, which may lead to different responses of the PFTs to changes in forcing (Fulton et al. 2003, Skogen \& Moll 2005, Mitra \& Davis 2010, Sailley et al. 2013). Most previous ecosystem model inter-comparisons have focused on changes in environmental drivers such as nutrient loads and climate change on water quality (e.g. Lenhart et al. 2010, Meier et al. 2012a, Skogen et al. 2014). A few studies have focused on the sensitivity of lower trophic levels to different formulations of predator-prey interactions, and the strength and complexity of zooplankton grazing dynamics (Anderson et al. 2013, Hashioka et al. 2013, Sailley et al. 2013, Le Quéré et al. 2016). These studies showed that food web dynamics, especially the predator-prey interactions, are very sensitive to the model formulations and gave different results of phytoplankton biomass within the same area. However, to our knowledge, 
there has not been a comprehensive model inter-comparison study of lower trophic level responses to the same change of mortality at the highest zooplankton trophic level.

In a first step towards using ecosystem models to describe potential trophic cascades at the base of the food web induced by changes in top-down forcing, the present study applied the same zooplankton mortality scenarios across seven, previously validated 3D ecosystem models. The ecosystem models represented four types of food webs based on their trophic structure and interactions and covered three areas. The aim of the study was to predict the response of summer phytoplankton biomass to changes in top-down forcing i) among models within the same area (the North Sea or the Baltic Sea) and ii) across areas using the same model (i.e. the North Sea versus the Baltic Sea and the North Sea versus the Nordic Seas). The variability was expected to be high within areas due to differences in model formulation and across areas due to differences in ecosystem dynamics.

\section{Methods and Material}

\subsection{Approach}

We compared simulation results across seven different 3D models covering three different domains in the NE Atlantic Ocean (Figure 1) yielding 10 model set-ups in total (Table 1). The models considered in this study have been thoroughly described and validated in the list of papers given in Table 1 . The data sources and time periods used for model validations are shown in Table 2. Hence, only the directly relevant features concerning the model food-web structure are outlined here (Figure 2). The models were set-up for a "Baseline" (corresponding to the published set-ups) and two "top-down" scenarios representing changes in the background mortality (model closure term) of the highest trophic level named ' $Z 1$ '. The background mortality term encompasses a range of processes and was described either as: linear $=c \cdot Z 1$, quadratic $=c \cdot Z 1^{2}$, and saturation $=c \cdot Z 1 \cdot Z 1 /(Z 1+k)$ functions, where $c$ is the closure term 
constant and $k$ is the mortality half-saturation constant (Table 1). The closure term constant $(c)$ was changed by $+/-20 \%$ in the P20 and M20 scenarios, respectively, which is within the natural variability of zooplankton mortality (Ji et al. 2013, Maar et al. 2014). In some models, other mortality terms such as cannibalism or death due to anoxia were explicitly described, but remained at their baseline values in the scenarios. The modelled period in Baseline and top-down scenarios covered a period of 3 years from 2003-2005 for most models except for HBM-ERGOM and POLCOMS-ERSEM using the years 2002-2004. The spin-up time varied from 2 to 10 years depending on the model.

\subsection{Study areas}

The three different domains covered by the models were: A) the North Sea (Delft3D-GEM, NORWECOMNS, MIRO\&CO, ECOSMO-NS, HBM-ERGOM-NS, POLCOMS-ERSEM), B) the Baltic Sea (MOM-ERGOM, ECOSMO-BS, HBM-ERGOM-BS) and C) the Nordic Seas (NORWECOM-NO) (Figure 1). Hence, the North Sea was covered by six models, the Baltic Sea by three models and the Nordic Seas by one model. The domains of the North Sea models were not identical, but outputs were estimated for the same area corresponding to the model domain of DELFT3D-GEM $\left(-3.2-9.0^{\circ} \mathrm{E}, 49.3-56.7^{\circ} \mathrm{N}\right)$ except for the MIRO\&CO model, which only covered the southern part of the North Sea (extracted for $49.3-52.5^{\circ} \mathrm{N}$ ). The model results for the Baltic Sea were extracted from the same area $\left(11.0-30.3^{\circ} \mathrm{E}, 54.0-65.9^{\circ} \mathrm{N}\right)$. The Nordic Seas model domain covered the Greenland Sea, the Iceland Sea, the Norwegian Sea and the Barents Sea $\left(-30.0-60.0^{\circ} \mathrm{E}, 61.3-80.0^{\circ} \mathrm{N}\right)$.

\subsection{Model descriptions}

For simplicity and ease of comparison among model responses to changes in top-down forcing, we only considered phyto- and zoo-PFTs and ignored grazing on bacteria and detritus in the analysis (Figure 2). The zoo-PFTs and phyto-PFTs were labelled as Z1-3 and P1-4, respectively, depending on the number of PFTs in each model. The Z1 group corresponds to the highest trophic level, and constitutes the group for 
which the $+/-20 \%$ change in background mortality was applied in the "top-down" scenarios. Nutrient uptake by the phyto-PFTs was also simplified to competition for one resource (e.g. nitrogen or phosphorous) in the schematic representations in Figure 2. In all models, the diet of each zoo-PFT was determined dynamically by the relative abundances of its prey, but weighted with statically defined food preference factors (Table 3). In most models, there were no differences in the quality (C:N:P-ratio) of prey for zooplankton growth; in the Delft3D-GEM and POLCOMS-ERSEM, however, prey stoichiometry could vary with time, space and/or species, which could influence zooplankton growth. Complexity of the models was defined by i) the number of trophic links $(L)$ per number of PFTs $(L / S)$ and ii) connectance $\left(C=L / S^{2}\right)$ i.e. the ratio of trophic links over the number of possible links (Dunne et al. 2002). Among the models, four types of food webs were depicted based on the trophic structure and interactions (Figure 2, Table 1):

Food web type 1: One zoo-PFT (Z1) grazes on several phyto-PFTs with low $L / S$ and low connectance in DELFT3D-GEM and MOM-ERGOM (Figure 2A).

In Delft3D-GEM (the North Sea), zooplankton (Z1) feeds on diatoms (P1), photoautotrophic flagellates (P2), the colony-forming Phaeocystis (P3) and dinoflagellates (P4) with different prey preferences (Table 3). The background mortality is a saturation function of the $Z 1$ biomass.

In MOM-ERGOM (the Baltic Sea), zooplankton (Z1) feeds on diatoms (P1) and photoautotrophic flagellates (P2) with equal prey preferences and on diazotophic cyanobacteria (P3) with lower preference (Table 3). The background mortality is a quadratic function of the Z1 biomass and a loss term due to hypoxia is expressed as increased respiration.

Food web type 2: Two zoo-PFTs and several phyto-PFTs interact with low $L / S$ and low connectance as applied in the models NORWECOM (-NO, -NS) and MIRO\&CO (Figure 2B). 
In NORWECOM (the North Sea and the Nordic Seas), omnivorous mesozooplankton (Z1) feeds on diatoms (P1) and microzooplankton (Z2), while microzooplankton feeds on photoautotrophic flagellates (P2), all with equal prey preferences (Table 3). The background mortality is a saturation function of the Z1 biomass.

In MIRO\&CO (the southern North Sea), omnivorous mesozooplankton (Z1) feeds on diatoms (P1) and microzooplankton (Z2), while microzooplankton feeds on photoautotrophic nanoflagellates (P2), all with equal prey preferences (Table 3). Phaeocystis colonies (P3) are not grazed, but can be disrupted into single edible cells (P2). The background mortality is a quadratic function of the $\mathrm{Z} 1$ biomass.

Food web type 3: Two zoo-PFTs and three phyto-PFTs interacts with intermediate $L / S$ and high connectance in the models ECOSMO and HBM-ERGOM (Figure 2C).

In ECOSMO (the North Sea and Baltic Sea), omnivorous zooplankton feeds on diatoms (P1), photoautotrophic flagellates (P2), diazotophic cyanobacteria (P3) and on herbivorous zooplankton (Z2), while Z2 feeds on all phyto-PFTs with different prey preferences (Table 3). The background mortality is a linear function of the Z1 biomass.

In HBM-ERGOM (the North Sea and the Baltic Sea), omnivorous mesozooplankton feeds on diatoms (P1), photoautotrophic flagellates (P2), diazotophic cyanobacteria (P3) and microzooplankton (Z2), while $\mathrm{Z2}$ grazes on the three phyto-PFTs. Prey preferences are lower for diazotophic cyanobacteria and Z2 than for the other PFTs (Table 3). Background mortality is described as a saturation function of the Z1 biomass and mortality due to cannibalism and hypoxia was explicitly described for both zoo-FTPs.

Food web type 4: Three zoo-PFTs and four phyto-PFTS interact with high $L / S$ and intermediate connectance in POLCOMS-ERSEM (Figure 2D). 
POLCOMS-ERSEM (the North Sea) includes omnivores mesozooplankton (Z1), microzooplankton (Z2) and heterotrophic flagellates (Z3), diatoms (P1), microphytoplankton (P2), nanophytoplankton (P3) and picophytoplankton (P4) with complex predator-prey interactions and different prey preferences (Table 3 , Figure 2D). The background mortality is a linear function of the $\mathrm{Z1}$ biomass and cannibalism is explicitly resolved as part of the predation for all three zoo-FTPs.

\subsection{Model output}

Average plankton biomass was calculated from model outputs for the summer period (June to September) in the upper $50 \mathrm{~m}$ of the water column. The response of each PFT was estimated as the relative change $(\Delta C)$ in biomass between the mortality scenarios $(S C E)$ and the Baseline $(B)$ with respect to the Baseline value and normalized by the change in forcing $(F=0.20)$ (Petersen et al. 2017):

$$
\Delta C_{P F T}=\frac{(S C E-B)}{B \times F}
$$

An absolute value $<1$ indicates that the response is smaller than the impact, whereas an absolute value $>1$ means that the impact is amplified by the system. For the zooplankton group Z1, the relative change of biomass will inform on the direct effect of the change of the forcing (mortality of Z1). For other groups, these values will inform about the indirect effect of the forcing (fx change in grazing pressure from Z1) and the dampening role of the food web structure complexity. Total summer phytoplankton biomass (PHY) was estimated as the sum of all phyto-PFTs (P1+P2+P3+P4). In addition, for an intermodel and inter-region comparison, we aggregated the individual model values of $\Delta C_{P H Y}$ for i) the same area over different models and ii) the same model over different areas. From that, we calculated the median $\Delta C_{P H Y}$ (due to skewness of data) as a measure for the typical food web response and the data range (=maximum-minimum) as a measure of the variability of $\Delta C_{P H Y}$ between individual models or regions. 
In order to evaluate the major responses to changes in top-down forcing (Figure 2), we estimated the ratios of $\Delta C s$ (from eq. 1 ) between each predator and its prey for all trophic links:

$$
L_{P, Z}=\frac{\Delta C_{\text {prey }}}{\Delta C_{\text {predator }}}
$$

We identified those direct links where the ratio was negative (i.e. opposite responses of predator and prey), which indicates a top-down forcing via skipped-level transmission (Casini et al. 2008, Heath et al. 2014). These links and their strengths are shown in Figure 2 for each model. The food web response was termed as 'direct grazing' if only 1 trophic link was involved, as a 'trophic cascade' if subsequent trophic links (e.g. Z1-Z2-P2) all responded with negative $L_{P, Z}-$ ratios or as 'combined' if it exhibited both direct grazing and trophic cascades. Hence, food web type 1 models with one zoo-PFT (1 trophic link) can only show a direct grazing response, which in most cases would lead to a negative $L_{p, z}-$ ratio. However, it is possible that changes in grazing pressure on different phytoplankton groups competing for a limiting nutrient will favor certain phytoplankton groups and result in a positive $L_{p, z}$-ratio for some (but not all) phyto-PFTs (Wollrab et al. 2012).

Finally, the trophic cascade $(T C)$-ratio was used to estimate the cascade strength of total phytoplankton biomass $(P H Y)$ in relation to changes in the highest zooplankton trophic level $(Z 1)$ :

$$
T C=\frac{\Delta C_{P H Y}}{\Delta C_{Z 1}}
$$

based on the estimated $\Delta C_{P H Y}$ and $\Delta C_{Z 1}$ from eq. 1 . When the $T C$-ratio is negative, $Z 1$ and $P H Y$ change in the opposite direction (positive or negative) and vice versa. If the TC-ratio is close to one (absolute numbers), the cascade strength is strong with little or no dampening. If the TC-ratio is close to zero (i.e. low change of $\left.\Delta C_{P H Y}\right)$, the cascade is dampened quickly, while a $T C$-ratio larger than one indicates that the cascade is amplified. 


\section{Results}

\subsection{Overall responses to top-down forcing}

The impact of changes in top-down forcing on summer phytoplankton biomass and different PFTs was analyzed using a high diversity of ecosystem models with different representations of the structure and function of lower trophic levels. First, the highest trophic level, i.e. the zoo-PFT Z1 directly impacted by the change in forcing, showed expected responses in the opposite direction than the change in the background mortality across all models (Figure 3A). The global median $\Delta C_{z 1}$ value was -0.65 in P20 and 0.73 in M20 for all models and regions (Table 4). The absolute value of $\Delta C_{Z 1}$ was less than 1 in most model results (14 out of 20 ) indicating an attenuation of the impact strength despite the direct impact on Z1. Amplification of the Z1-response was found in the type 3 models, i.e. ECOSMO-NS-BS (P20 and M20) and HBM-ERGOM-NS-BS (M20).

Second, the indirect effects of changes in top-down forcing were analyzed for trophic levels lower than Z1. Conversely to the direct responses, changes in total summer phytoplankton biomass $\left(\Delta C_{P H Y}\right)$ varied between the models for each scenario, both in direction (positive/negative) and magnitude (Figure 3B). The $\Delta C_{P H Y}$ showed generally an opposite response direction to that of Z1 except for NORWECOM-NS-NO and ECOSMO-NS (P20). The median of $\Delta C_{P H Y}$ was 0.10 (range: -0.36 to 0.64 ) in P20 and -0.11 (range: -0.35 to 0.34 ) in M20 across all models (Table 4). When comparing zooplankton and phytoplankton relative changes in biomass, the $T C$-ratio (eq. 3 ) was negative in most cases (i.e. opposite responses) except for the NORWECOM models (Figure 3C). ECOSMO-NS (P20) also gave a negative TCratio during the averaging procedure (months and grid cells) despite the negative signs of both $\Delta C_{z 1}$ and $\Delta C_{P H Y}$ on total average (Table 4) probably due to non-linear responses in the food web. The median TCratio was -0.14 (range: -0.67 to 0.48 ) in $\mathrm{P} 20$ and -0.18 (range: -0.58 to 0.32 ) in $\mathrm{M} 20$ (Table 4 ) and overall 
-0.17 in both scenarios. Hence, there was a general dampening of the signal from Z1 to phytoplankton biomass.

3.2. Inter-model comparison: The North Sea

\subsubsection{Responses between models and food web types}

The North Sea was covered by six models (DELFT3D, NORWECOM-NS, MIRO\&CO, ECOSMO-NS, HBMERGOM-NS and POLCOMS-ERSEM) representing four different types of food webs with median $\Delta C_{P H Y}$ of 0.06 and -0.15 in P20 and M20, respectively (Table 5). The inter-model variability of $\Delta C_{P H Y}($ range $=1.00)$ was high in comparison with the other areas and the overall model variability (Table 5).

In the food web type 1 model (DELFT3D-GEM), there was only one zoo-PFT (Z1) grazing mainly on P1 (diatoms) or P4 (dinoflagellates) with negative $L_{P, Z}$-ratios (Figure $2 \mathrm{~A}$, Table 4 ). The other two phyto-PFTs (P2 and P3) showed, on the other hand, a positive $L_{P, z}-$ ratios, because they were influenced by the differentiated grazing pressure and competition for a limiting nutrient. The $\Delta C_{P H Y}$ values had the same response direction as the North Sea median values, but were slightly higher with 0.23 and -0.25 in P20 and $M 20$, respectively (Table 4, Figure $3 \mathrm{~A}$ ).

The food web type 2 models (NORWECOM-NS and MIRO\&CO, Figure 2B) showed the strongest responses in terms of $\Delta C_{P H Y}$ values and $T C$-ratios (Figure 3B-C). This food web type was characterized by two branches that were looped through the top consumer (Z1) and had a low connectance. Opposed to the other North Sea models, the TC-ratios in NORWECOM-NS were positive with 0.32 and 0.48 in P20 and $\mathrm{M} 20$, respectively (Table 4). The positive ratios could be explained by a strong trophic cascade in the Z1-Z2-P2 branch (causing the same response direction for Z1 and PHY) compared to a weaker grazing effect in the Z1-P1 branch, probably due to the high overlap of Z2 and P2 biomasses during summer (Figures 2B, 3, 4). The other type 2 model, MIRO\&CO in the southern North Sea, showed on the contrary 
the most negative $T C$-ratios among all the models with -0.58 and -0.67 in P20 and M20, respectively (Table 4). Here, the grazing response observed in the Z1-P1 branch was stronger than in the Z1-Z2-P2 branch (Figure 2B), probably because the P1 (diatom) biomass was higher than for P2 (flagellates) (Figure 4B). There was indication of a bottom-up effect (competition for nutrients) in the P2-Z2 branch, because both were affected in the same direction as Z1 (Figure 2B).

The food web type 3 models were characterized by having two zoo-PFTs and high connectance. ECOSMO-NS showed skewed responses of $\Delta C_{P H Y}$ with negative values in both scenarios $(-0.18$ and -0.19 in P20 and M20, respectively) (Table 4). The Z1 PFT (omnivorous zooplankton) dominated the total summer zooplankton biomass (97\%) and P2 (flagellates) the total summer phytoplankton biomass (96\%) (Figure 4), which allowed different types of model responses to changes in top-down forcing. When the grazing impact by Z1 decreased (P20), this allowed Z2 (herbivorous zooplankton) to increase considerably $\left(\Delta C_{\mathrm{Zz}}=5.76\right)$ and initiated a strong trophic cascade in the Z1-Z2-P2 branch leading to negative $\Delta C_{P H Y}$ values (same direction between $\mathrm{Z1}$ and PHY). In the opposite situation (M20), the increased grazing pressure by $\mathrm{Z} 1$ reduced both $\mathrm{Z2}\left(\Delta C_{\mathrm{Z2}}=-2.60\right), \mathrm{P} 1$ and $\mathrm{P} 2$ leading to negative $\Delta C_{P H Y}$ values (opposite direction between Z1 and PHY) (Figure 3, Table 4). In the other food web type 3 model, HBM-ERGOM-NS, the resultant $\Delta C_{P H Y s}$ were 0.10 and -0.11 in $\mathrm{P} 20$ and $M 20$, respectively, and hence less strong than for ECOSMO-NS (Table 4). The major grazer pathways (Z1 grazing on P2 and Z2) were similar to the M20 response in ECOSMO-NS (Figure 3C). The zoo-PFTs were also subject to cannibalism. The Z1 (mesozooplankton) biomass (69\% of total zoo-PFTs) and P2 (flagellates) biomass (73\% of total phytoPFTs) also dominated the summer plankton biomasses, but to a lesser extent than in ECOSMO-NS (Figure 4).

In the food web type 4 model (POLCOMS-ERSEM), the predator-prey interactions were the most complex with several major grazer pathways in the scenarios compared to the other food webs (Figure 
2D). There was a direct grazing response between $\mathrm{Z} 1$ and $\mathrm{P} 2 \mathrm{in}$ addition to trophic cascades in the branches Z1-Z2-P3 and Z1-Z2-Z3, both involving the Z2 group (Figure 3D). In addition, the three zoo-PFTs were subject to cannibalism. The different responses counteracted each other and overall resulted in a weak $\Delta C_{P H Y}$ of 0.03 and -0.03 in P20 and M20, respectively (Table 4).

\subsubsection{Spatial patterns of phytoplankton biomass changes in the North Sea}

Spatial patterns of responses (magnitude and direction) in summer phytoplankton biomass $\left(\Delta C_{P H Y}\right)$ to changes in top-down forcing in the North Sea were highly variable between the models (Figure 5). In five of the six North Sea models (DELFT3D-GEM, NORWECOM-NS, MIRO\&CO, HBM-ERGOM-NS and POLCOMS-ERSEM), $87-100 \%$ of the area showed the same response direction of $\Delta C_{P H Y}$ in $\mathrm{P} 20$ and M20 (Table 6), but with opposite response direction for NORWECOM-NS (as explained before). ECOSMO-NS showed, on the other hand, the highest spatial heterogeneity of $\Delta C_{P H Y}$ with only $67 \%$ and $76 \%$ in P20 and M20, respectively, of the areas showing the same (negative) response direction (Figure 5D). The high spatial variability in ECOSMO-NS was due to the competition between two pathways in the food web (Z1-P2 or Z1-Z2-P2), which had different outcomes in different areas. Hence, local areas could have either negative or positive values within the same model and scenario and, hence, not necessarily in the same response direction as the area-averaged result (Figure 3B-C). The strongest responses (either negative or positive) were observed in the German Bight and the English Channel (southeastern shallowest parts) in most models except for POLCOMS-ERSEM with lowest responses in this area.

\subsection{Inter-model comparison: The Baltic Sea}

The Baltic Sea was covered by three models (MOM-ERGOM, ECOSMO-BS and HBM-ERGOM-BS), which represented two different types of food webs ( 1 and 3) with $\Delta C_{P H Y}$ median of 0.11 and -0.11 in P20 and M20, respectively (Table 5). Despite their differences, the three models provided similar results of 
zooplankton and total phytoplankton changes in the Baltic Sea (Figure 3). The variability of $\Delta C_{P H Y}$ was relatively low (range $=0.33$ ) compared to the North Sea and the overall model variability (Table 5). The overall TC-ratios were negative (from -0.09 to -0.19 ), i.e. the opposite response between $\mathrm{Z} 1$ and phytoplankton biomass (Table 4). The direct grazing response by Z1 on different phytoplankton prey dominated the models, whereas the trophic cascade through Z2 (food web type 3 models) was weaker (Figures 2A and C). Spatially, the responses were in the same direction in MOM-ERGOM and HBMERGOM-BS, whereas in ECOSMO-BS the response was more diverse (Table 6, Figure 6). However, in all three models, the highest changes $\left(\Delta C_{P H Y}\right)$ were estimated in the high productive coastal and shallow areas and in the same response direction (Figure 6).

\subsection{Inter-regional model comparison}

Three of the models covered two areas; NORWECOM-NS-NO, ECOSMO-NS-BS and HBM-ERGOM-NS-BS. The internal model variability expressed as the range of $\Delta C_{P H Y}$ within each model (including the two areas) was highest for NORWECOM with the range $=0.70$ followed by ECOSMO with the range $=0.38$ and lowest for HBM-ERGOM with the range= 0.21 (Table 5). NORWECOM exhibited four to five times stronger responses of $\Delta C_{P H Y}$ in the North Sea than for the Nordic Seas (Figures 3B, C). The inter-regional variability of $\Delta C_{P H Y}$ in NORWECOM was lower than the inter-model variability of the North Sea models, but higher than for the Baltic Sea models (Table 5). In ECOSMO, the internal variability of $\Delta C_{P H Y}$ was higher than for the Baltic Sea models, but lower than for the North Sea models (Figure 3, Table 4). In HBM-ERGOM, variability of $\Delta C_{P H Y}$ was generally lower than for the Baltic Sea and North Sea models (Figure 3B, C). 


\section{Discussion}

\subsection{Top-down mediated trophic cascades}

The present study provides new knowledge on the role of top-down mediated trophic cascades and its parameterization in lower trophic level ecosystem models by applying the same top-down scenarios to a wide range of 3D dynamic ecosystem models. The top-down scenarios were expressed as a change in the background mortality of the highest trophic level, Z1, which showed opposite responses to the change in forcing (Figure 3A). In most cases, there was an attenuation of the response by Z1 due to a dilution effect at the open boundaries, other mortality terms (e.g. anoxia, cannibalism) or complex food web interactions (e.g. bottom-up effects) counterbalancing the top-down effects (Wollrab et al. 2012). Amplification of the Z1-response was found in the type 3 models (i.e. ECOSMO and HBM-ERGOM) probably due to positive feedback mechanisms from the trophic cascades in the food web (Wollrab \& Diehl 2015). Overall, there was a general dampening of the signal from the highest trophic level (Z1) to phytoplankton biomass (i.e. an absolute $T C$-ratio less than one, Figure $3 C$ ), which is a common feature of aquatic food webs due to internal trophic interactions (Shurin et al. 2002, Andersen \& Pedersen 2010, Heath et al. 2014). However, phytoplankton responses varied in both magnitude and direction (positive/negative) relative to the change in Z1 depending on the food web structure and trophic coupling represented in the models (Figures 2, 3B).

The model results emphasized that the second zooplankton group (Z2) played an important role as mediator of trophic cascades. In most cases, the Z2 exhibited opposite grazing pressures on the phytoPFTs compared to Z1 (Figure 2, Table 4) and thereby dampened the total phytoplankton biomass responses to changes in Z1 (i.e. less negative TC-ratio). In NORWECOM, the trophic cascades in the Z1Z2-P2 branch even overruled the direct grazing pressure by Z1 on phytoplankton biomass and caused a positive TC-ratio. The Z2-PFT covers a wide range of species with different sizes, growth rates, prey 
preference, mixotrophy and feeding strategies (Hansen 1991), which makes it difficult to define them as a functional group and to parameterize the general physiological processes (Anderson et al. 2013, Sailley et al. 2013). According to our model results from NORWECOM, MIRO\&CO and HBM-ERGOM, Z2 had a biomass similar to Z1 (31-77\% of total), whereas in ECOSMO, Z2 comprised 3\% of the zooplankton biomass (Figure 4A). However, the Z2-PFT plays different roles in different models as e.g. herbivorous zooplankton in ECOSMO, ciliates and heterotrophic dinoflagellates in HBM-ERGOM and a broader range of microzooplankton in NORWECOM. POLCOMS-ERSEM included both microzooplankton (Z2) and heterotrophic flagellates (Z3), comprising $16 \%$ and $28 \%$, respectively, of total zooplankton biomass (Figure 4A). Consequently, a direct comparison of Z2 between models is complicated by the lack of common metrics (Sailley et al. 2013). There is, to our knowledge, no coherent data set on microzooplankton (Z2) for the North Sea and the Baltic Sea (Quéré et al. 2005, Bils et al. 2017). An accurate model parameterization of this PFT is challenging without the necessary calibration data. This issue is reflected in the relatively few attempts to validate the biomass of different zoo-PFTs based on available national monitoring-, research- and 'other' data sets (Table 2). For the Z1-PFT (often assumed to represent copepods), more data sets from e.g. the Continuous Plankton Recorder (Pitois \& Fox 2006), national monitoring data and research data were available allowing a validation of Z1 biomass in most models (Table 2).

\subsection{Effects on summer phytoplankton biomass}

The change in summer phytoplankton biomass showed overall opposite responses relative to the change of Z1. Hence, a higher mortality of Z1 (scenario P20) was shown to increase the summer phytoplankton biomass and thereby affect the water quality negatively in marine waters as suggested by previous studies (Frank et al. 2005, Casini et al. 2008, Llope et al. 2011). In the North Sea, a previous 
model study using size-selective predation by Atlantic herring (Clupea harengus), four zoo-PFTs and two phyto-PFTs also found that top-down control should be present in the system (Koslow 1983). However, analysis of field data from 50 years showed no sign of top-down forced trophic cascades affecting the phytoplankton despite intense fishing activities in the North Sea (Koslow 1983, Reid et al. 2000). These studies suggested that trophic cascades in the North Sea disappeared due to ecosystem-wide fishing on most species, that zooplankton was more food limited than predation limited or that complex food web interactions dampened the response (Koslow 1983, Reid et al. 2000, Andersen \& Pedersen 2010). For the Baltic Sea, the scenarios results in P20 (decrease of Z1) are consistent with field data over a 30-year period showing that overfishing of cod population directly affected its main prey, European sprat (Sprattus sprattus), and indirectly caused a reduction in summer zooplankton and higher summer phytoplankton biomass (Casini et al. 2008, Möllmann et al. 2008). The responses were analyzed with respect to the summer period, but will probably be different other times of the year due the seasonal plankton community succession (e.g. the spring diatom bloom) and change in environmental conditions (e.g. light, nutrient levels).

\subsection{Inter-model comparison: the North Sea}

The highest inter-model variability was found for the North Sea covered by six models (Table 5). The inter-model median for the North Sea predicted that changes in top-down forcing could affect the summer phytoplankton biomass although the responses varied in magnitude and direction both spatially and between models. The high variability in model responses was mainly due to the food web type 2 models (NORWECOM-NS and MIRO\&CO, Figure 2B), which showed the strongest responses in terms of $\Delta C_{P H Y}$ values and $T C$-ratios (Figures 3B-C). These models with two branches were very sensitive to top-down forcing, because it was possible for one of the two branches to dominate the response depending on the spatial-seasonal overlap of predator-prey distributions. A dominant trophic cascade 
response in one of the branches is consistent with theoretical models for an odd-length food chain (McCann et al. 1998a, Cury et al. 2003, Wollrab et al. 2012, Heath et al. 2014). In the food web type 1 model DELFT3D-GEM, the differentiated grazing pressure and competitive ability for a shared nutrient favored some phyto-PFTs on behalf of others in agreement with theoretical models (Wollrab et al. 2012). In food web type 3 models, ECOSMO-NS and HBM-ERGOM-NS, the different model parameterizations of grazing interactions (e.g. grazing rates, prey preferences and cannibalism) resulted in a different sensitivity of the lower trophic levels to changes in top-down forcing in P20, whereas the responses in M20 were more similar. The missing trophic cascade in HBM-ERGOM-NS was due to internal attenuation of the signal from top-down forcing by the prescribed cannibalism within Z2 (not present in ECOSMO-NS) indicated by the lower $\Delta C_{Z 2}$ compared to ECOSMO-NS (Table 4). It was previously demonstrated that inclusion of zooplankton interference (e.g. cannibalism) weakened trophic interactions in a theoretical food web model and better matched the patterns found in nature (Mccann et al. 1998b). Hence, the food web type 3 responses were more complex than the more rigid food web types 1 and 2 models and therefore more difficult to predict in relation to changes in top-down forcing. In the food web type 4 model (POLCOMS-ERSEM), the more complex and compensating food web interactions dampened the response to changes in top-down forcing. This is in agreement with previous studies, which showed that increased complexity in model structures stabilized the system with a higher resistance to perturbations (Mccann et al. 1998b, Vallina \& Le Quéré 2011, Vallina et al. 2017).

In top-down scenarios, the skipped-level-transmission complicates the prediction of responses at various trophic levels and the choice of model parameters and food web structure becomes even more important and should be appropriate for the study area. In comparison, ecosystem models are expected to give more similar results in bottom-up scenarios (e.g. changes in nutrient inputs), because of the direct link between nutrients and phytoplankton and responses typically will be in the same direction as the forcing (Cury et al. 2003, Heath et al. 2014). In addition to the food web definition, additional model 
components, such as the choice of nutrient cycles, remineralization rates and benthic-pelagic coupling would be indirectly affected by changes in the Z1 mortality and additionally lead to response variability among different ecosystem models. Hence, a priori assumptions on food web structure and parameterization will influence cascades and pathways in model estimates and, thus, become highly relevant when examining ecosystem pressures such as fishing and climate change.

\subsection{Spatial patterns}

Spatial variability of the phytoplankton responses was generally high in the North Sea and the Baltic Sea indicating that not only the specification of trophic links, but also temperature and nutrient dynamics play vital roles for ecosystem response to top-down effects. Strong horizontal gradients of temperatures and nutrient concentrations are typically found at the interface between coastal and offshore areas. Especially in the North Sea, bathymetric features and strong tides result in the formation of mixed, stratified and frontal regions that are characterized by very different hydrographic features (Otto et al. 1990). Higher temperatures can strengthen trophic interactions since zooplankton respiration increases faster with warming than primary production (Scheffer et al. 2001, Maar \& Hansen 2011, Svensson et al. 2017). Likewise, higher nutrient concentrations may strengthen or weaken different grazer pathways and thereby interact with the top-down forced trophic cascades (Wollrab \& Diehl 2015, Petersen et al. 2017). Furthermore, spatial variations in top-down responses are also caused by spatial patterns in background mortality in the field (Fulton et al. 2003, Travers et al. 2009, Maar et al. 2014), a feature that could not be investigated by our experimental set-up. These diverse spatial responses make it difficult to support a coherent management plan with respect to sustainable fishing and water quality.

\subsection{Inter-regional model comparisons}


Strongest responses of NORWECOM were found in the shallow, well-mixed and highly productive southern North Sea (Figure 5C), whereas the phytoplankton responses were lower and more homogenously distributed in the Nordic Seas (Figure 6D). This difference could be related to the higher nutrient inputs and higher temperatures in the North Sea that can strengthen trophic interactions compared to the more nutrient limited, colder and less productive Nordic Seas (Frank et al. 2007, Wollrab \& Diehl 2015, Svensson et al. 2017). Hence, the higher variability of the North Sea models and partly the Baltic Sea models compared to the internal model variability still indicates that a priori assumptions in the food web structure and dynamics will influence trophic cascades and pathways arising from the same change in top-down forcing (Sailley et al. 2013, Heath et al. 2014). In principle, the model response of a single model can be highly variable in different regions, indicating that ecosystem functioning and hydrographic characteristics, and not only model formulations, were driving the responses to top-down forcing.

\subsection{Conclusions}

There was a high variability in the responses across models, especially in the North Sea, due to the different food web structures and trophic couplings represented in the models. Especially the role of the zoo-PFTs seems important for the resulting model response to top-down forcing and highlights a challenge in ecosystem modelling. The model-dependent responses to the same forcing demonstrate the uncertainty that arises from simplifying real-world ecosystems into numerically tractable model systems. This needs to be taken into account when confronting models tuned to present-day dynamics using what-if scenarios, e.g. by discussing their outcome as a possible, rather than a predicted, reaction of the ecosystem. In the present state of model development, an ensemble of model simulations seems as a reasonable approach to reduce inherent uncertainty in model estimates and provide weight of evidence (Lenhart et al. 2010, Meier et al. 2012b, Queiros et al. 2016, Yun et al. 2017). The behavior of 
the relatively simple ecosystem models used here, should be compared to potentially more complex behavior and trophic responses of trait-based models, which can include many more groups (or a blending across groups in terms of size-spectrum models) to better understand how changes in topdown forcing may cascade through the plankton community. For a better representation of trophic cascades, the ecosystem models could be coupled to higher trophic level models (e.g. fish production models) or provide input to 'End-to-End' models considering food web interactions for all trophic levels including human pressures (Fulton 2010, Shin et al. 2010, Utne et al. 2012). 


\section{Acknowledgements}

This work was initiated on a meeting with the ICES Working Group on Integrative, Physical-biological, and Ecosystem Modelling (WGIPEM) in March 2015. The work was supported by the EU grant "Vectors

of Change in Oceans and Seas, Marine Life, Impact and Economic Sectors" (Vectors, FP7/2010-2013) and The Danish Council for Strategic Research to the project "Integrated Management of Agriculture, Fishery, Environment and Economy" (IMAGE, grant no. 09-067259). 


\section{References}

Aksnes DL, Ulvestad KB, Balino BM, Berntsen J, Egee JK, Svendsen E (1995) Ecological modelling in coastal waters-towards predictive physical-chemical-biological simulation models. Ophelia 41:536

Andersen K, Pedersen M (2010) Damped trophic cascades driven by fishing in model marine ecosystems. Proc R Soc B 277:795-802

Anderson TR, Hessen DO, Mitra A, Mayor DJ, Yool A (2013) Sensitivity of secondary production and export flux to choice of trophic transfer formulation in marine ecosystem models. J Mar Syst 125:41-53

Bils F, Moyano M, Aberle N, van Damme CJG, Loots C, Nash RDM, Kloppmann M, Peck MA (2017) Abundance, composition and broadscale distribution of protozooplankton during winter in the North Sea. in prep

Blackford JC, Allen JI, Gilbert FJ (2004) Ecosystem dynamics at six contrasting sites: a generic modelling study. J Mar Syst 52:191-215

Blauw AN, Los HFJ, Bokhorst M, Erftemeijer PLA (2009) GEM: a generic ecological model for estuaries and coastal waters. Hydrobiologia 618:175-198

Butenschön M, Clarke J, Aldridge AL, Allen JI, Artioli Y, Blackford J, Bruggeman J, Cazenave P, Ciavatta S, Kay S, Lessin G, Van Leeuwen SM, Van der Molen J, de Mora L, Polimene L, Sailley S, Stephens N, Torres R (2016) ERSEM 15.06: a generic model for marine biogeochemistry and the ecosystem dynamics of the lower trophic levels. Geosci Model Dev 9:1339

Carpenter SR, Kitchell JF, Hodgson JR (1985) Cascading Trophic Interactions and Lake Productivity. Bioscience 35:634-639

Casini M, Lovgren J, Hjelm J, Cardinale M, Molinero JC, Kornilovs G (2008) Multi-level trophic cascades in a heavily exploited open marine ecosystem. Proc R Soc B 275:1793-1801

Cury P, Shannon L, Shin YJ (2003) The functioning of marine ecosystems: a fisheries perspective. In: Sinclair M, Valdimarsson $G$ (eds) Responsible Fisheries in the Marine Ecosystem. FAO

Daewel U, Hjøllo SS, Huret M, Ji R, Maar M, Niiranen S, Travers-Trolet M, Peck MA, van de Wolfshaar KE (2014) Predation control of zooplankton dynamics: a review of observations and models. ICES J Mar Sci 71:254-271

Daewel U, Schrum C (2013) Simulating long-term dynamics of the coupled North Sea and Baltic Sea ecosystem with ECOSMO II: Model description and validation. J Mar Syst 119:30-49

Daewel U, Schrum C, Gupta AK (2015) The predictive potential of early life stage individual-based models (IBMs): an example for Atlantic cod Gadus morhua in the North Sea. Mar Ecol Prog Ser 534:199-219

Dunne JA, Williams RJ, Martinez ND (2002) Food-web structure and network theory: The role of connectance and size. Proc Natl Acad Sci USA 99:12917-12922

Edwards AM, Yool A (2000) The role of higher predation in plankton population models. J Plankton Res 22:1085-1112

Frank KT, Petrie B, Choi JS, Leggett WC (2005) Trophic cascades in a formerly cod-dominated ecosystem. Science 308:1621-1623

Frank KT, Petrie B, Shackell NL (2007) The ups and downs of trophic control in continental shelf ecosystems. Trends Ecol Evol 22:236-242

Fulton EA (2010) Approaches to end-to-end ecosystem models. J Mar Syst 81:171-183

Fulton EA, Sinith ADM, Johnson CR (2003) Mortality and predation in ecosystem models: is it important how these are expressed? Ecol Model 169:157-178 
Hansen PJ (1991) Quantitative importance and trophic role of heterotrophic dinoflagellates in a coastal pelagial food web. Mar Ecol Prog Ser 73:253-262

Hansson LA, Annadotter H, Bergman E, Hamrin SF, Jeppesen E, Kairesalo T, Luokkanen E, Nilsson PA, Sondergaard M, Strand J (1998) Biomanipulation as an application of food-chain theory: Constraints, synthesis, and recommendations for temperate lakes. Ecosystems 1:558-574

Hashioka T, Vogt M, Yamanaka Y, Le Quéré C, Buitenhuis ET, Aita MN, Alvain S, Bopp L, Hirata T, Lima I, Sailley S, Doney SC (2013) Phytoplankton competition during the spring bloom in four plankton functional type models. Biogeosciences 10:6833-6850

Heath MR, Speirs DC, Steele JH (2014) Understanding patterns and processes in models of trophic cascades. Ecol Lett 17:101-114

HELCOM (2013) Summary report on the development of revised Maximum Allowable Input (MAI) and updated Country Allocated Reduction Targets (CART) of the Baltic Sea Plan.

Hjøllo SS, Huse G, Skogen M, Melle W (2012) Modelling secondary production in the Norwegian Sea with a fully coupled physical/primary production/individual-based Calanus finmarchicus model system. Mar Biol Res 8:508-526

Holt J, Butenschoen M, Wakelin S, Artioli Y, Allen J, I (2012) Oceanic controls on the primary production of the northwest European continental shelf: model experiments under recent past conditions and a potential future scenario. Biogeosciences 9:97-117

Huse G, Holst JC, Utne K, Nottestad L, Melle W, Slotte A, Ottersen G, Fenchel T, Uiblein F (2012) Effects of interactions between fish populations on ecosystem dynamics in the Norwegian Sea - results of the INFERNO project Preface. Mar Biol Res 8:415-419

Ji RB, Stegert C, Davis CS (2013) Sensitivity of copepod populations to bottom-up and top-down forcing: a modeling study in the Gulf of Maine region. J Plankton Res 35:66-79

Koslow JA (1983) Zooplankton Community Structure in the North Sea and Northeast Atlantic: Development and Test of a Biological Model. Can J Fish Aquat Sci 40:1912-1924

Lacroix G, Ruddick K, Park Y, Gypens N, Lancelot C (2007) Validation of the 3D biogeochemical model MIRO\&CO with field nutrient and phytoplankton data and MERIS-derived surface chlorophyll a images. J Mar Syst 64:66-88

Lancelot C, Spitz Y, Gypens N, Ruddick K, Becquevort S, Rousseau V, Lacroix G, Billen G (2005) Modelling diatom and Phaeocystis blooms and nutrient cycles in the Southern Bight of the North Sea: the MIRO model. Mar Ecol Prog Ser 289:63-78

Le Quéré C, Buitenhuis ET, Moriarty R, Alvain S, Aumont O, Bopp L, Chollet S, Enright C, Franklin DJ, Geider RJ, Harrison SP, Hirst AG, Larsen S, Legendre L, Platt T, Prentice IC, Rivkin RB, Sailley S, Sathyendranath S, Stephens N, Vogt M, Vallina SM (2016) Role of zooplankton dynamics for Southern Ocean phytoplankton biomass and global biogeochemical cycles. Biogeosciences 13:4111-4133

Leibold MA, Holyoak M, Mouquet N, Amarasekare P, Chase JM, Hoopes MF, Holt RD, Shurin JB, Law R, Tilman D, Loreau M, Gonzalez A (2004) The metacommunity concept: a framework for multiscale community ecology. Ecol Lett 7:601-613

Lenhart HJ, Mills DK, Baretta-Bekker H, van Leeuwen SM, van der Molen J, Baretta JW, Blaas M, Desmit X, Kuhn W, Lacroix G, Los HJ, Menesguen A, Neves R, Proctor R, Ruardij P, Skogen MD, Vanhoutte-Brunier A, Villars MT, Wakelin SL (2010) Predicting the consequences of nutrient reduction on the eutrophication status of the North Sea. J Mar Syst 81:148-170

Lewis K, Allen JI, Richardson AJ, Holte JT (2006) Error quantification of a high resolution coupled hydrodynamic-ecosystem coastal-ocean model: Part3, validation with Continuous Plankton Recorder data. J Mar Syst 63:209-224

Lindegren M, Möllmann C, Hansson LA (2010) Biomanipulation: a tool in marine ecosystem management and restoration? Ecol Appl 20:2237-2248 
Llope M, Daskalov GM, Rouyer TA, Mihneva V, Chan KS, Grishin AN, Stenseth NC (2011) Overfishing of top predators eroded the resilience of the Black Sea system regardless of the climate and anthropogenic conditions. Global Change Biol 17:1251-1265

Los FJ, Blaas M (2010) Complexity, accuracy and practical applicability of different biogeochemical model versions. J Mar Syst 81:44-74

Los FJ, Villars MT, Van der Tol MWM (2008) A 3-dimensional primary production model (BLOOM/GEM) and its applications to the (southern) North Sea (coupled physical-chemical-ecological model). J Mar Syst 74:259-294

McCann K, Hastings A, Huxel GR (1998a) Weak trophic interactions and the balance of nature. Nature 395:794-798

Mccann KS, Hastings A, Strong DR (1998b) Trophic cascades and trophic trickles in pelagic food webs. Proc R Soc B 265:205-209

Meier HEM, Andersson HC, Arheimer B, Blenckner T, Chubarenko B, Donnelly C, Eilola K, Gustafsson BG, Hansson A, Havenhand J, Hoglund A, Kuznetsov I, MacKenzie BR, Muller-Karulis B, Neumann T, Niiranen S, Piwowarczyk J, Raudsepp U, Reckermann M, Ruoho-Airola T, Savchuk OP, Schenk F, Schimanke S, Vali G, Weslawski JM, Zorita E (2012a) Comparing reconstructed past variations and future projections of the Baltic Sea ecosystem-first results from multi-model ensemble simulations. Environ Res Lett 7

Meier HEM, Muller-Karulis B, Andersson HC, Dieterich C, Eilola K, Gustafsson BG, Hoglund A, Hordoir R, Kuznetsov I, Neumann T, Ranjbar Z, Savchuk OP, Schimanke S (2012b) Impact of Climate Change on Ecological Quality Indicators and Biogeochemical Fluxes in the Baltic Sea: A Multi-Model Ensemble Study. Ambio 41:558-573

Mitra A, Davis C (2010) Defining the "to" in end-to-end models. Prog Oceanogr 84:39-42

Myers RA, Worm B (2003) Rapid worldwide depletion of predatory fish communities. Nature 423:280283

Möllmann C, Mueller-Karulis B, Kornilovs G, St John MA (2008) Effects of climate and overfishing on zooplankton dynamics and ecosystem structure: regime shifts, trophic cascade, and feedback coops in a simple ecosystem. ICES J Mar Sci 65:302-310

Maar M, Hansen JLS (2011) Increasing temperatures change pelagic trophodynamics and the balance between pelagic and benthic secondary production in a water column model of the Kattegat. J Mar Syst 85:57-70

Maar M, Markager S, Madsen KS, Windolf J, Lyngsgaard MM, Andersen HE, Møller EF (2016) The importance of local versus external nutrient loads for $\mathrm{Chl}$ a and primary production in the Western Baltic Sea. Ecol Model 320:258-272

Maar M, Møller EF, Larsen J, Madsen KS, Wan ZW, She J, Jonasson L, Neumann T (2011) Ecosystem modelling across a salinity gradient from the North Sea to the Baltic Sea. Ecol Model 222:16961711

Maar M, Rindorf A, Møller EF, Christensen A, Madsen KS, van Deurs M (2014) Zooplankton mortality in 3D ecosystem modelling considering variable spatial-temporal fish consumptions in the North Sea. Prog Oceanogr 124:78-91

Neumann T, Fennel W, Kremp C (2002) Experimental simulations with an ecosystem model of the Baltic Sea: A nutrient load reduction experiment. Glob Biogeochem Cycles 16

Neumann T, Radtke H, Seifert T (2017) On the importance of Major Baltic Inflows for oxygenation of the central Baltic Sea. J Geophys Res Oceans 122:1090-1101

Neumann T, Siegel H, Gerth M (2015) A new radiation model for Baltic Sea ecosystem modelling. J Mar Syst 152:83-91

Otto L, Zimmerman JTF, Furnes GK, Mork M, Saetre R, Becker G (1990) Review of the Physical Oceanography of the North-Sea. Netherlands Journal of Sea Research 26:161-238 
Pace ML, Cole JJ, Carpenter SR, Kitchell JF (1999) Trophic cascades revealed in diverse ecosystems. Trends Ecol Evol 14:483-488

Peck MA, Arvanitidis C, Butenschön M, Canu DM, Chatzinikolaou E, Cucco A, Domenici P, Fernandes JA, Gasche L, Huebert KB, Hufnagl M, Jones MC, Kempf A, Keyl F, Maar M, Mahévas S, Marchal P, Nicolas D, Pinnegar JK, Rivot E, Rochette S, Sell AF, Sinerchia M, Solidoro C, Somerfield PJ, Teal LR, Travers-Trolet M, van de Wolfshaar KE (2018) Projecting changes in the distribution and productivity of living marine resources: A critical review of the suite of modelling approaches used in the large European project VECTORS. Estuar Coast Shelf Sci 201:40-55

Petersen ME, Maar M, Larsen J, Møller EF, Hansen PJ (2017) Trophic cascades of bottom-up and topdown forcing on nutrients and plankton in the Kattegat, evaluated by modelling. J Mar Syst 169:15-39

Pitois SG, Fox CJ (2006) Long-term changes in zooplankton biomass concentration and mean size over the Northwest European shelf inferred from Continuous Plankton Recorder data. ICES J Mar Sci 63:785-798

Polis GA, Sears ALW, Huxel GR, Strong DR, Maron J (2000) When is a trophic cascade a trophic cascade? Trends Ecol Evol 15:473-475

Queiros AM, Huebert KB, Keyl F, Fernandes JA, Stolte W, Maar M, Kay S, Jones MC, Hamon KG, Hendriksen G, Vermard Y, Marchal P, Teal LR, Somerfield PJ, Austen MC, Barange M, Sell AF, Allen I, Peck MA (2016) Solutions for ecosystem-level protection of ocean systems under climate change. Global Change Biol 22:3927-3936

Quéré CL, Harrison SP, Colin Prentice I, Buitenhuis ET, Aumont O, Bopp L, Claustre H, Cotrim Da Cunha L, Geider R, Giraud X, Klaas C, Kohfeld KE, Legendre L, Manizza M, Platt T, Rivkin RB, Sathyendranath S, Uitz J, Watson AJ, Wolf-Gladrow D (2005) Ecosystem dynamics based on plankton functional types for global ocean biogeochemistry models. Global Change Biol 11:2016-2040

Reid PC, Battle EJV, Batten SD, Brander KM (2000) Impacts of fisheries on plankton community structure. ICES J Mar Sci 57:495-502

Sailley SF, Vogt M, Doney SC, Aita MN, Bopp L, Buitenhuis ET, Hashioka T, Lima I, Le Quere C, Yamanaka $Y$ (2013) Comparing food web structures and dynamics across a suite of global marine ecosystem models. Ecol Model 261:43-57

Saux Picart S, Butenschön M, Shutler JD (2012) Wavelet-based spatial comparison technique for analysing and evaluating two-dimensional geophysical model fields. Geosci Model Dev 5:223230

Scheffer M, Carpenter S, de Young B (2005) Cascading effects of overfishing marine systems. Trends Ecol Evol 20:579-581

Scheffer M, Straile D, van Nes EH, Hosper H (2001) Climatic warming causes regime shifts in lake food webs. Limnol Oceanogr 46:1780-1783

Schrum C, St John M, Alekseeva I (2006) ECOSMO, a coupled ecosystem model of the North Sea and Baltic Sea: Part II. Spatial-seasonal characteristics in the North Sea as revealed by EOF analysis. J Mar Syst 61:100-113

Schulz J, Mollmann C, Hirche HJ (2007) Vertical zonation of the zooplankton community in the Central Baltic Sea in relation to hydrographic stratification as revealed by multivariate discriminant function and canonical analysis. J Mar Syst 67:47-58

Shin YJ, Travers M, Maury O (2010) Coupling low and high trophic levels models: Towards a pathwaysorientated approach for end-to-end models. Prog Oceanogr 84:105-112

Shurin JB, Borer ET, Seabloom EW, Anderson K, Blanchette CA, Broitman B, Cooper SD, Halpern BS (2002) A cross-ecosystem comparison of the strength of trophic cascades. Ecol Lett 5:785-791 
Skogen MD, Budgell WP, Rey F (2007) Interannual variability in Nordic seas primary production. ICES J Mar Sci 64:889-898

Skogen MD, Eilola K, Hansen JL, Meier H, Molchanov MS, Ryabchenko VA (2014) Eutrophication status of the North Sea, Skagerrak, Kattegat and the Baltic Sea in present and future climates: A model study. J Mar Syst 132:174-184

Skogen MD, Mathisen LR (2009) Long-term effects of reduced nutrient inputs to the North Sea. Estuarine Coastal and Shelf Science 82:433-442

Skogen MD, Moll A (2005) Importance of ocean circulation in ecological modeling: An example from the North Sea. J Mar Syst 57:289-300

Skogen MD, Svendsen E, Berntsen J, Aksnes D, Ulvestad KB (1995) Modeling the Primary Production in the North-Sea Using A Coupled 3-Dimensional Physical-Chemical-Biological Ocean Model. Estuar Coast Shelf Sci 41:545-565

Svensson F, Karlsson E, Gardmark A, Olsson J, Adill A, Zie J, Snoeijs P, Eklof JS (2017) In situ warming strengthens trophic cascades in a coastal food web. Oikos 126:1150-1161

Travers M, Shin YJ (2010) Spatio-temporal variability in fish-induced predation mortality on plankton: A simulation approach using a coupled trophic model of the Benguela ecosystem. Prog Oceanogr 84:118-120

Travers M, Shin YJ, Jennings S, Cury P (2007) Towards end-to-end models for investigating the effects of climate and fishing in marine ecosystems. Prog Oceanogr 75:751-770

Travers M, Shin YJ, Jennings S, Machu E, Huggett JA, Field JG, Cury PM (2009) Two-way coupling versus one-way forcing of plankton and fish models to predict ecosystem changes in the Benguela. Ecol Model 220:3089-3099

Utne KR, Hjollo SS, Huse G, Skogen M (2012) Estimating the consumption of Calanus finmarchicus by planktivorous fish in the Norwegian Sea using a fully coupled 3D model system. Mar Biol Res 8:527-547

Vallina SM, Cermeno P, Dutkiewicz S, Loreau M, Montoya JM (2017) Phytoplankton functional diversity increases ecosystem productivity and stability. Ecol Model 361:184-196

Vallina SM, Le Quéré C (2011) Stability of complex food webs: Resilience, resistance and the average interaction strength. J Theor Biol 272:160-173

Wollrab S, Diehl S (2015) Bottom-up responses of the lower oceanic food web are sensitive to copepod mortality and feeding behavior. Limnol Oceanogr 60:641-656

Wollrab S, Diehl S, De Roos AM (2012) Simple rules describe bottom-up and top-down control in food webs with alternative energy pathways. Ecol Lett 15:935-946

Yun K, Hsiao J, Jung M-P, Choi I-T, Glenn DM, Shim K-M, Kim S-H (2017) Can a multi-model ensemble improve phenology predictions for climate change studies? Ecol Model 362:54-64 
Table 1. Overview of the applied models and their domains, food web types (see Figure 2), number of zoo-PFTs, number of total PFTs (S) i.e. not including resources, number of trophic links $(L)$, links per PFT $(L / S)$, connectance $\left(C=L / S^{2}\right)$, mesozooplankton background mortality function and 3 model references. The model domains are the North Sea (NS), the Baltic Sea (BS) and the Nordic Seas (NO).

4

\begin{tabular}{|c|c|c|c|c|c|c|c|c|c|}
\hline Model name & $\begin{array}{l}\text { Model } \\
\text { domain }\end{array}$ & $\begin{array}{l}\text { Food web } \\
\text { type }\end{array}$ & $\begin{array}{l}\text { Zoo- } \\
\text { PFTs }\end{array}$ & $S$ & $L$ & $L / S$ & $L / S^{2}$ & $\begin{array}{l}\text { Background } \\
\text { mortality }\end{array}$ & References \\
\hline DELFT3D-GEM & NS & 1 & 1 & 5 & 4 & 0.80 & 0.16 & saturation & (Los et al. 2008, Blauw et al. 2009, Los \& Blaas 2010) \\
\hline MIRO\&CO & S. NS & 2 & 2 & 5 & 4 & 0.80 & 0.16 & quadratic & (Lancelot et al. 2005, Lacroix et al. 2007) \\
\hline NORWECOM & NS, NO & 2 & 2 & 4 & 3 & 0.75 & 0.19 & saturation & $\begin{array}{l}\text { (Aksnes et al. 1995, Skogen et al. 1995, Skogen et al. 2007, Skogen \& } \\
\text { Mathisen 2009, Hjøllo et al. 2012) }\end{array}$ \\
\hline ECOSMO & NS, BS & 3 & 2 & 5 & 7 & 1.40 & 0.28 & linear & (Schrum et al. 2006, Daewel \& Schrum 2013, Daewel et al. 2015) \\
\hline HBM-ERGOM & NS, BS & 3 & 2 & 5 & 7 & 1.40 & 0.28 & saturation & (Maar et al. 2011, 2014, 2016, Petersen et al. 2017) \\
\hline POLCOMS-ERSEM & NS & 4 & 3 & 7 & 12 & 1.71 & 0.24 & linear & $\begin{array}{l}\text { (Lewis et al. 2006, Holt et al. 2012, Saux Picart et al. 2012, Butenschön et } \\
\text { al. 2016) }\end{array}$ \\
\hline MOM-ERGOM & BS & 1 & 1 & 4 & 3 & 0.75 & 0.19 & quadratic & (Neumann et al. 2002, 2015, 2017) \\
\hline
\end{tabular}


Table 2. Data sources used for model validation of nutrient concentrations, biomass of different phyto-PFT's, Chl $a$ concentration, primary 7 production, biomass of different zoo-PFT's and Z1 biomass. I=ICES data, $\mathrm{H}=\mathrm{HELCOM}$ data, $\mathrm{N}=$ National monitoring data, $\mathrm{C}=\mathrm{Continuous} \mathrm{Plankton}$ 8 Recorder ( $C P R)$ data, $W=$ World Ocean Atlas, $R=$ research projects, $R S=$ remote sensing data, $L=$ literature values and $\mathrm{O}=$ other data (e.g. $\mathrm{PhD}$ 9 project). The last column shows the validation period for the different variables. Validation references are shown in Table 1.

\begin{tabular}{|c|c|c|c|c|c|c|c|}
\hline Model name & Nutrients $^{a}$ & $\begin{array}{l}\text { Phyto- } \\
\text { PFT's }\end{array}$ & Chl ac & $\begin{array}{l}\text { Primary } \\
\text { production }^{\mathrm{d}}\end{array}$ & Zoo-PFT'se & Z1 biomass ${ }^{f}$ & Validation period \\
\hline DELFT3D-GEM & $N, R$ & $N, R$ & $N, R, R S$ & - & Not relevant & $\mathrm{L}$ & a,c) $1975-2012$ b) 1998 f) 2008 \\
\hline MIRO\&CO & $N, R, O$ & $R, O$ & $\mathrm{~N}, \mathrm{R}, \mathrm{O}, \mathrm{RS}$ & - & $\mathrm{R}, \mathrm{O}$ & $\mathrm{R}, \mathrm{O}$ & a,b,c,e,f) 1989-1999 and a,b,c) 1991-2003 \\
\hline NORWECOM-NS & I, N, R & - & I, N, R & $L, R, O$ & - & - & a, c) $1980-2006$, d) 1985-1994 \\
\hline NORWECOM-NO & - & - & $\mathrm{N}, \mathrm{RS}$ & $\mathrm{L}$ & - & $\mathrm{N}, \mathrm{L}$ & c) $1981-2007$, d) $1981-2006$, f) $1997-2007$ \\
\hline ECOSMO & $\mathrm{I}, \mathrm{H}$ & $\mathrm{I}, \mathrm{W}$ & 1 & L & - & $\mathrm{R}, \mathrm{C}$ & a,d) $1970-2008, b, c$, f) $1984-1986$ and f) 1995 \\
\hline HBM-ERGOM & $\mathrm{I}, \mathrm{H}, \mathrm{N}, \mathrm{W}$ & - & $\mathrm{I}, \mathrm{H}, \mathrm{N}$ & $\mathrm{N}$ & $\mathrm{N}$ & $\mathrm{N}, \mathrm{C}$ & a) 2001-2006, c-d) 2001-2010, e) 2010 and f) 2001-2004 \\
\hline POLCOMS-ERSEM & $\mathrm{I}, \mathrm{W}$ & C & I, RS, W & $\mathrm{L}$ & - & C & $\begin{array}{l}\text { a, c) 1970-2004 (I), a, c) 1981-2004 (W), c) 2003-2004 (RS), } \\
\text { d) bulk values and b, f) 1988-1989 }\end{array}$ \\
\hline MOM-ERGOM & $\mathrm{I}, \mathrm{H}, \mathrm{N}, \mathrm{R}$ & - & $\mathrm{I}, \mathrm{H}, \mathrm{N}$ & - & Not relevant & - & a) 2008-2013 and b) 1970-2008 \\
\hline
\end{tabular}


12 Table 3. Prey preferences of the different zoo-PFTs in the food web models (see Figure 2). In some models, the zoo-PFTs are subject to 13 cannibalism.

\begin{tabular}{|c|c|c|c|c|c|c|c|c|c|c|c|c|c|c|c|c|c|}
\hline \multirow{2}{*}{$\begin{array}{l}\text { Predator } \\
\text { prey }\end{array}$} & \multirow[t]{2}{*}{ Type } & \multicolumn{7}{|c|}{$\mathrm{Z1}$} & \multicolumn{6}{|c|}{$\mathrm{Z2}$} & \multicolumn{3}{|c|}{$\mathrm{Z3}$} \\
\hline & & P1 & P2 & P3 & P4 & $\mathrm{Z1}$ & $\mathrm{Z2}$ & Z3 & P1 & P2 & P3 & P4 & $\mathrm{Z2}$ & $\mathrm{Z3}$ & P3 & P4 & Z3 \\
\hline DELFT3D-GEM & 1 & 0.85 & 0.50 & 0.10 & 0.30 & - & - & - & - & - & - & - & - & - & - & - & - \\
\hline MOM-ERGOM & 1 & 1.00 & 1.00 & 0.20 & - & - & - & - & - & - & - & - & - & - & - & - & - \\
\hline NORWECOM & 2 & 1.00 & 0.00 & - & - & 0.00 & 1.00 & - & 0.00 & 1.00 & - & - & 0.00 & - & - & - & - \\
\hline MIRO\&CO & 2 & 1.00 & 0.00 & 0.00 & - & 0.00 & 1.00 & - & 0.00 & 1.00 & 0.00 & - & 0.00 & - & - & - & - \\
\hline ECOSMO & 3 & 0.85 & 0.10 & 0.30 & - & 0.00 & 0.15 & - & 0.25 & 0.70 & 0.30 & - & 0.00 & - & - & - & - \\
\hline HBM-ERGOM & 3 & 1.00 & 1.00 & 0.20 & - & 0.40 & 0.40 & - & 1.00 & 1.00 & 0.20 & - & 0.40 & - & - & - & - \\
\hline POLCOMS-ERSEM & 4 & 0.15 & 0.15 & 0.05 & 0.00 & 0.25 & 0.25 & 0.05 & 0.15 & 0.10 & 0.15 & 0.15 & 0.15 & 0.20 & 0.15 & 0.25 & 0.15 \\
\hline
\end{tabular}

14 
16 Table 4. The $\Delta C$ for each PFT and TC-ratios in scenarios P20 (top) and M20 (bottom) averaged from June to September in the upper $50 \mathrm{~m}$ and the 17 median for all models.

\begin{tabular}{|c|c|c|c|c|c|c|c|c|c|c|c|c|}
\hline P20 scenario & Domain & $\begin{array}{c}\text { Food web } \\
\text { type }\end{array}$ & $\Delta C_{Z 1}$ & $\Delta C_{Z 2}$ & $\Delta C_{Z 3}$ & $\Delta C_{z O O}$ & $\Delta C_{P 1}$ & $\Delta C_{P 2}$ & $\Delta C_{P 3}$ & $\Delta C_{P 4}$ & $\Delta C_{P H Y}$ & $T C$-ratio \\
\hline DELFT3D-GEM & NS & 1 & -0.70 & - & - & -0.70 & 0.47 & 0.17 & -0.39 & 0.10 & 0.23 & -0.24 \\
\hline MIRO\&CO & S. NS & 2 & -0.21 & -0.50 & - & -0.24 & 3.90 & -0.86 & -1.28 & 0.18 & 0.64 & -0.67 \\
\hline NORWECOM & NS & 2 & -0.60 & 0.59 & - & -0.01 & 0.16 & -0.43 & - & - & -0.36 & 0.48 \\
\hline ECOSMO & NS & 3 & -1.50 & 5.76 & - & -1.01 & 2.51 & -0.41 & 0.00 & - & -0.18 & -0.03 \\
\hline HBM-ERGOM & NS & 3 & -0.89 & 0.50 & - & -0.45 & 0.06 & 0.12 & 0.00 & - & 0.10 & -0.12 \\
\hline POLCOMS-ERSEM & NS & 4 & -0.22 & 0.29 & -0.10 & -0.09 & 0.02 & 0.21 & -0.09 & -0.05 & 0.03 & -0.21 \\
\hline MOM-ERGOM & BS & 1 & -0.49 & - & - & -0.49 & -0.10 & 0.18 & 0.12 & - & 0.11 & -0.29 \\
\hline ECOSMO & BS & 3 & -1.75 & 2.18 & - & -1.71 & 2.90 & -0.91 & 3.62 & - & 0.19 & -0.16 \\
\hline HBM-ERGOM & $\mathrm{BS}$ & 3 & -0.91 & 0.38 & - & -0.40 & 0.05 & 0.12 & 0.12 & - & 0.09 & -0.10 \\
\hline NORWECOM & NO & 2 & -0.59 & 0.07 & - & -0.09 & 0.05 & -0.08 & - & - & -0.07 & 0.13 \\
\hline P20 median & All & & -0.65 & 0.44 & -0.10 & -0.42 & 0.11 & 0.02 & 0.01 & 0.10 & 0.10 & -0.14 \\
\hline M20 scenario & Domain & $\begin{array}{c}\text { Food web } \\
\text { type }\end{array}$ & $\Delta C_{Z 1}$ & $\Delta C_{\mathrm{Z2}}$ & $\Delta C_{Z 3}$ & $\Delta C_{z O O}$ & $\Delta C_{P 1}$ & $\Delta C_{P 2}$ & $\Delta C_{P 3}$ & $\Delta C_{P 4}$ & $\Delta C_{P H Y}$ & $T C$-ratio \\
\hline DELFT3D-GEM & NS & 1 & 0.81 & - & - & 0.81 & -0.08 & 0.27 & 0.99 & -0.18 & -0.25 & -0.21 \\
\hline MIRO\&CO & S. NS & 2 & 0.29 & 0.36 & - & 0.19 & -1.72 & 1.62 & 1.26 & -0.05 & -0.35 & -0.58 \\
\hline NORWECOM & NS & 2 & 0.54 & -0.41 & - & 0.01 & -0.12 & 0.42 & - & - & 0.34 & 0.32 \\
\hline ECOSMO & NS & 3 & 1.85 & -2.60 & - & 1.40 & -2.93 & -0.11 & 0.00 & - & -0.19 & -0.33 \\
\hline HBM-ERGOM & NS & 3 & 1.21 & -0.63 & - & 0.61 & -0.07 & -0.13 & 0.00 & - & -0.11 & -0.10 \\
\hline POLCOMS-ERSEM & NS & 4 & 0.23 & -0.27 & 0.09 & 0.09 & -0.01 & -0.21 & 0.09 & 0.06 & -0.03 & -0.18 \\
\hline MOM-ERGOM & BS & 1 & 0.65 & - & - & 0.65 & 0.19 & -0.19 & -0.14 & - & -0.11 & -0.18 \\
\hline ECOSMO & BS & 3 & 2.86 & -2.68 & - & 2.75 & -2.26 & 1.60 & -1.49 & - & -0.14 & -0.19 \\
\hline HBM-ERGOM & BS & 3 & 1.29 & -0.49 & - & 0.56 & -0.07 & -0.14 & -0.05 & - & -0.11 & -0.09 \\
\hline NORWECOM & NO & 2 & 0.64 & -0.07 & - & 0.10 & -0.07 & 0.10 & - & - & 0.08 & 0.14 \\
\hline M20 median & All & & 0.73 & -0.45 & 0.09 & 0.58 & -0.08 & -0.01 & 0.00 & -0.05 & -0.11 & -0.18 \\
\hline
\end{tabular}


19 Table 5. Aggregated $\Delta C_{P H Y}$ results. The number $(N)$ of all results (P20 and M20), the number of models,

20 the median for $\mathrm{P} 20$ and $\mathrm{M} 20$ and the range=maximum-minimum values for both $\mathrm{P} 20$ and $\mathrm{M} 20$ for i)

21 each model area and ii) for the models covering two areas.

\begin{tabular}{|cccccc|}
\hline & & $\begin{array}{c}\text { Number of } \\
\text { models }\end{array}$ & $\begin{array}{c}\text { Median } \\
\text { P20 }\end{array}$ & $\begin{array}{c}\text { Median } \\
\text { M20 }\end{array}$ & $\begin{array}{c}\text { P20+M20 } \\
\text { range }\end{array}$ \\
\hline North Sea & 12 & 6 & 0.06 & -0.15 & 1.00 \\
Baltic Sea & 6 & 3 & 0.11 & -0.11 & 0.33 \\
Nordic Seas & 2 & 1 & -0.07 & 0.08 & 0.15 \\
\hline NORWECOM & 4 & 1 & -0.21 & 0.21 & 0.70 \\
ECOSMO & 4 & 1 & 0.00 & -0.17 & 0.38 \\
HBM-ERGOM & 4 & 1 & 0.10 & -0.11 & 0.21 \\
\hline All & 20 & 10 & 0.10 & -0.11 & 1.00 \\
\hline
\end{tabular}

23

24 
25 Table 6 . The $\%$ of grid cells in the model domains with negative values of $\Delta C_{P H Y}$ and $T C$-ratio.

\begin{tabular}{|lccccc|}
\hline \multirow{2}{*}{ Model } & \multirow{2}{*}{ Domain } & P20 & M20 & P20 & M20 \\
& & $\Delta C_{P H Y}$ & $\Delta C_{P H Y}$ & $T C$-ratio & $T C$-ratio \\
\hline DELFT3D-GEM & NS & 5 & 95 & 94 & 94 \\
MIRO\&CO & NS & 1 & 93 & 86 & 86 \\
NORWECOM & NS & 97 & 3 & 6 & 10 \\
ECOSMO & NS & 67 & 76 & 32 & 71 \\
HBM-ERGOM & NS & 0 & 100 & 100 & 100 \\
POLCOMS-ERSEM & NS & 9 & 87 & 91 & 87 \\
MOM-ERGOM & BS & 0 & 100 & 100 & 100 \\
ECOSMO & BS & 17 & 68 & 83 & 68 \\
HBM-ERGOM & BS & 1 & 99 & 99 & 100 \\
NORWECOM & NO & 99 & 2 & 2 & 2 \\
\hline
\end{tabular}

26

27

28 
Figure 1. Maps showing the study areas in the NE Atlantic Ocean (A) and the bathymetry of B) the Nordic Seas (NO), C) the North Sea (NS) and D) the Baltic Sea (BS). Bathymetry was obtained from GEBCO (www.gebco.net) and Natural Earth (www.naturalearthdata.com) datasets.

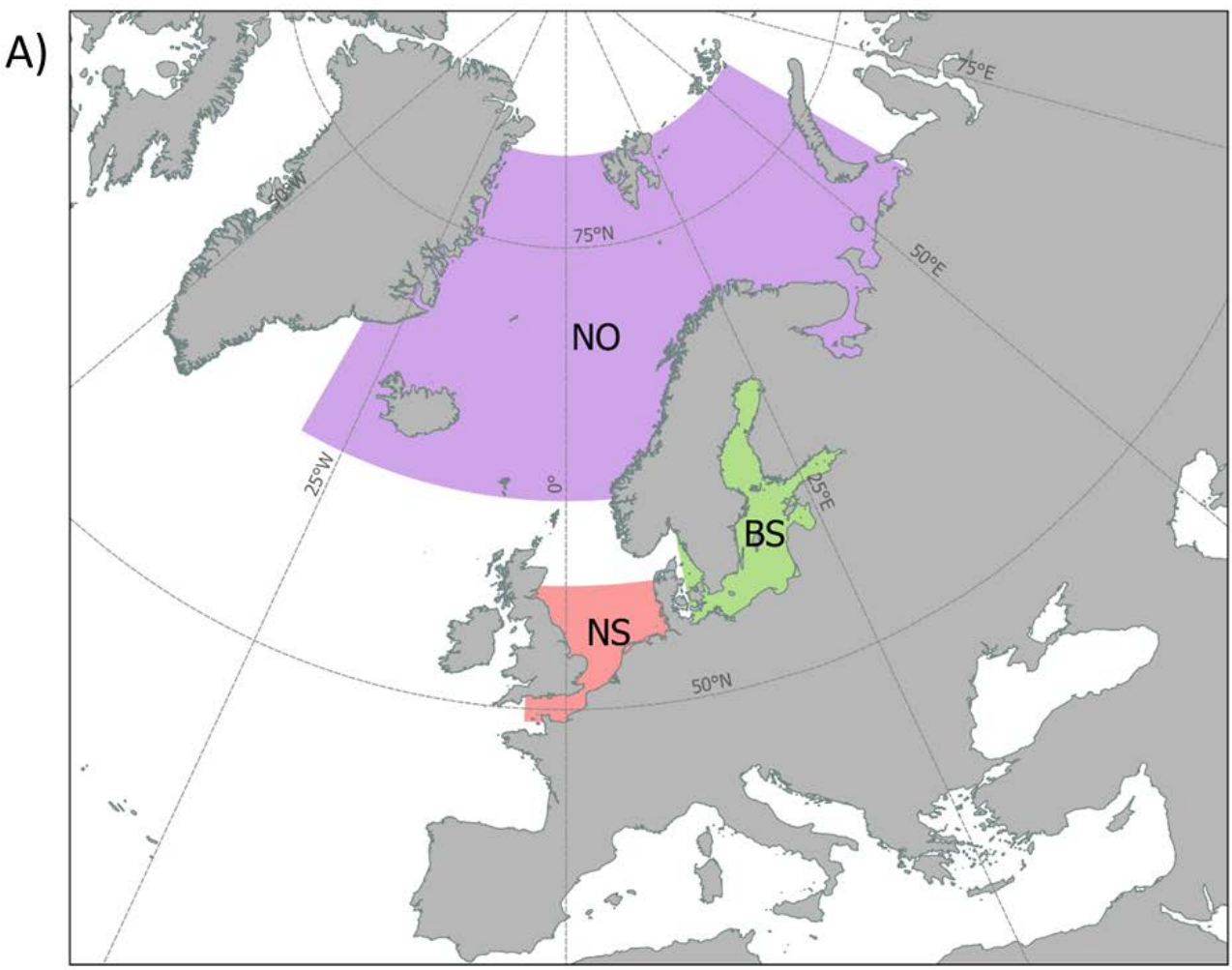

B)

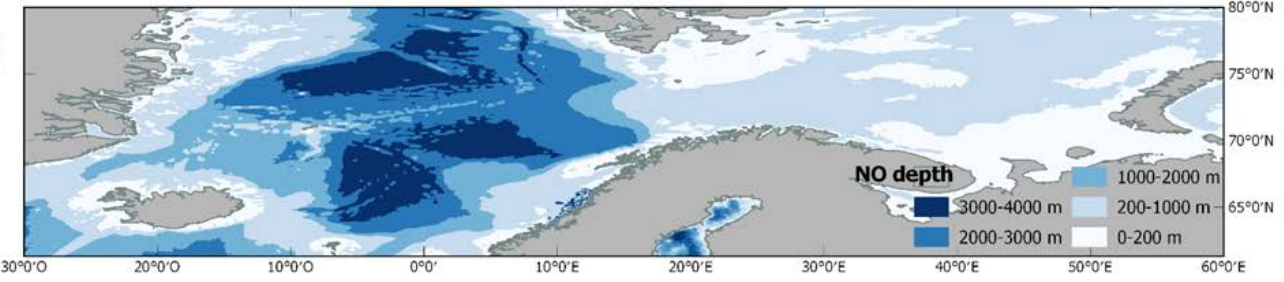

C)
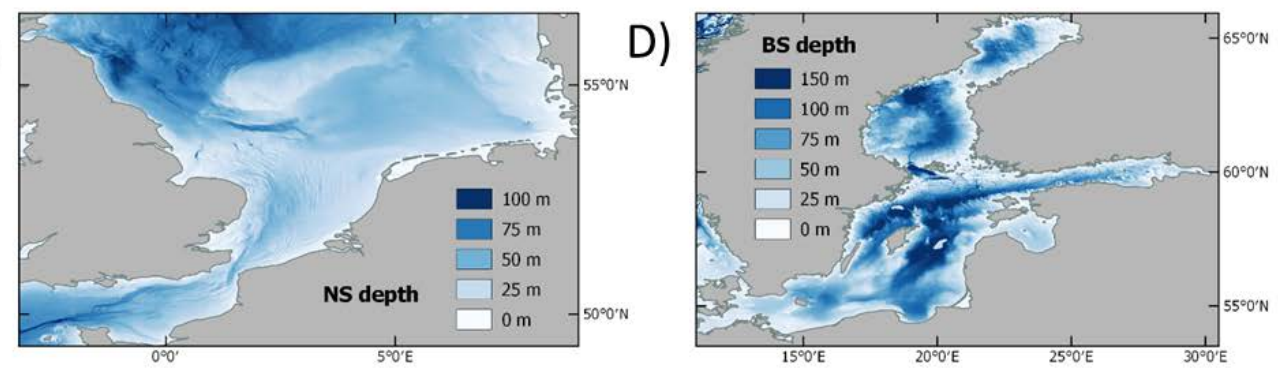
Figure 2. Conceptual diagrams of the four (A-D) food web types applied in the models. Circles indicate the nutrient resource (R) and the different zoo- $(Z)$ and phyto- (P) plankton functional types (PFTs). Arrows show the direction of the energy transfer. The grey arrow at the top indicates the modified background mortality of the highest trophic level (Z1). PFTs and trophic links with highest responses to changes in Z1 mortality are highlighted in bold. PFT responses opposite to that of Z1 are highlighted with grey background.
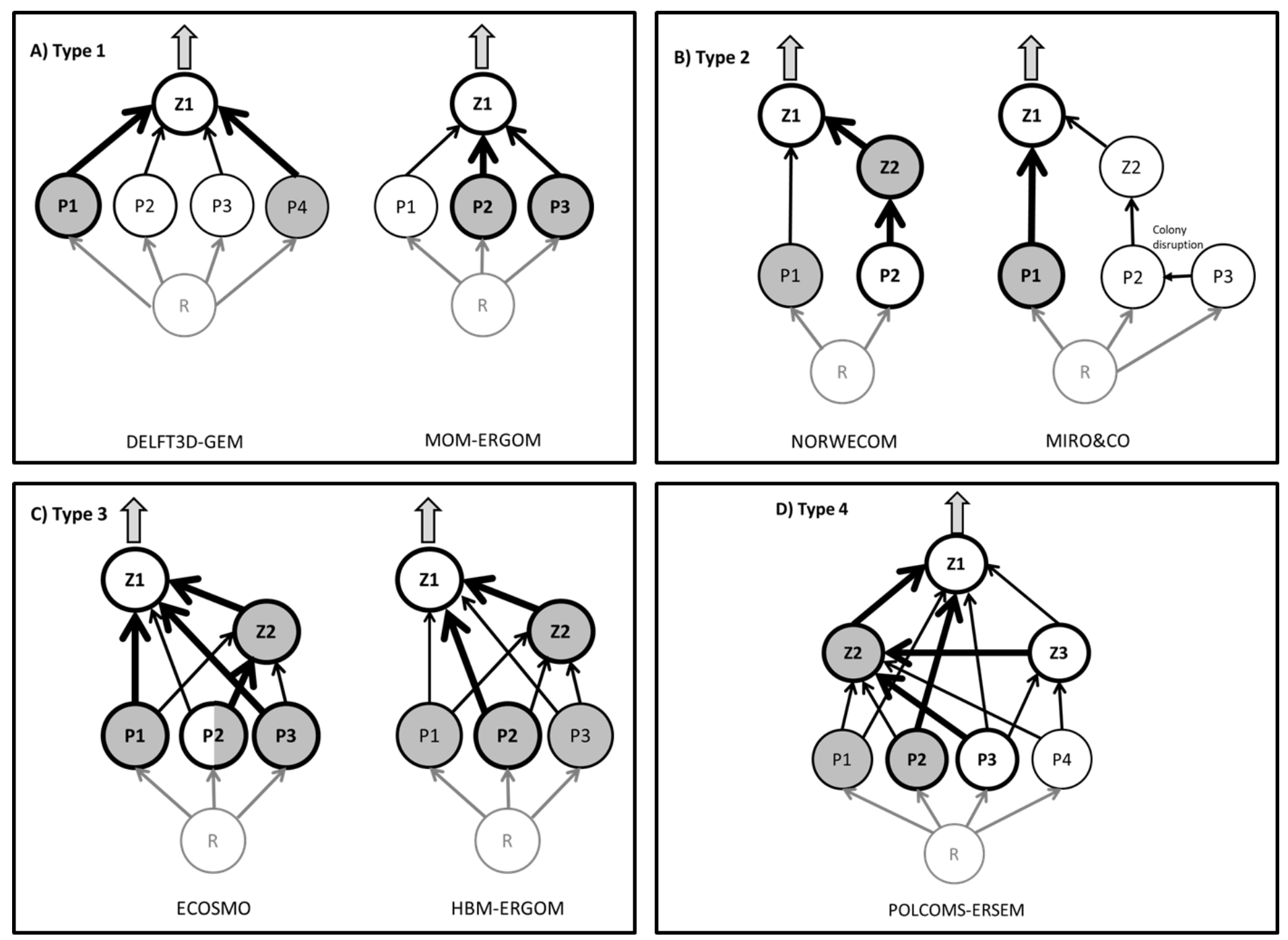
Figure 3. Summer means of $A)$ relative change in the biomass of the highest trophic level $\left.\left(\Delta C_{z 1}\right), B\right)$ relative change of total phytoplankton biomass $\left(\Delta C_{P H Y}\right)$ and $C$ ) the $T C$-ratio for the two scenarios (P2O and M20). The vertical separations indicate the different areas and the bottom numbers in A) indicate the food web type.

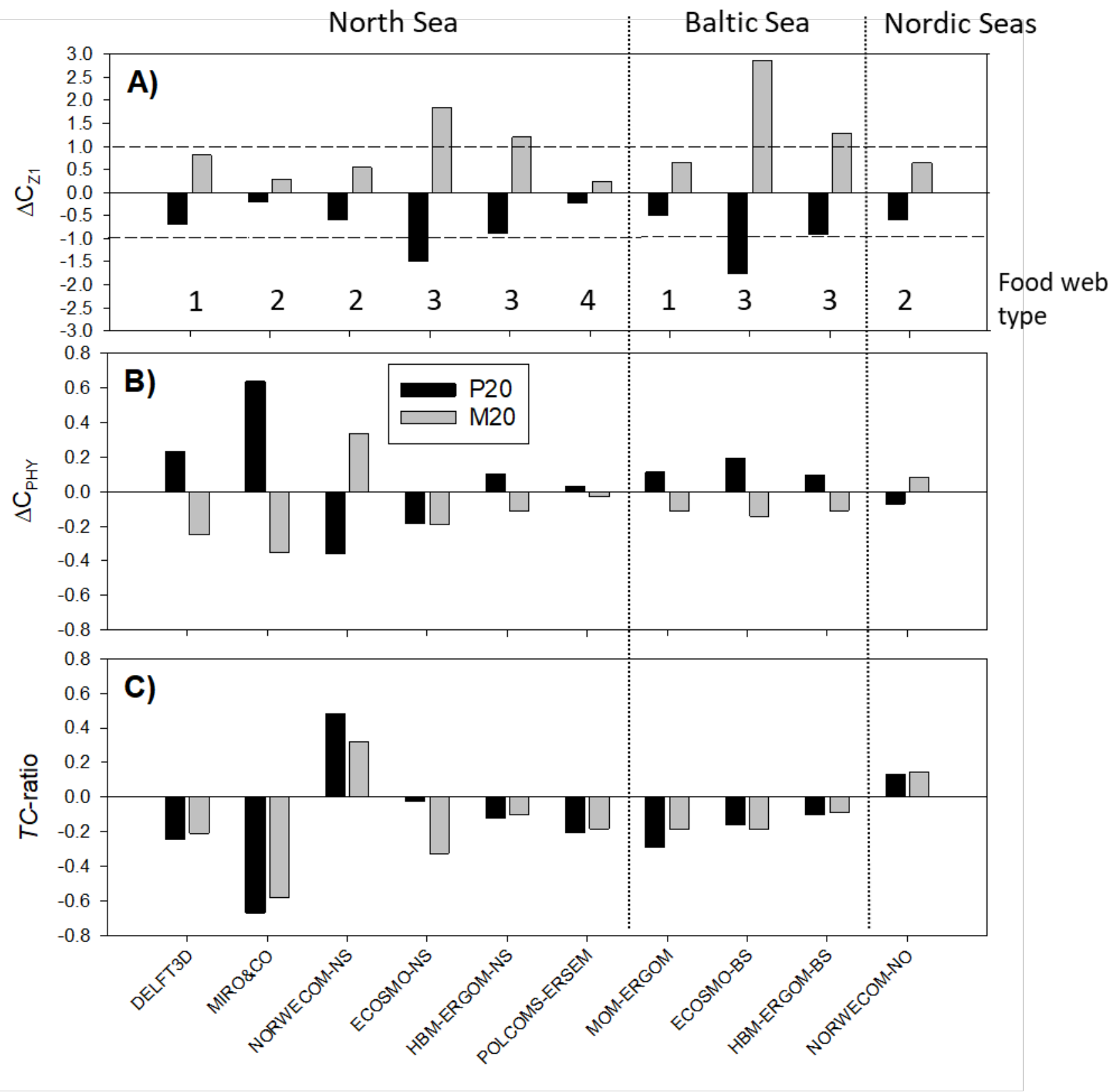


Figure 4. The \%-contributions of the different PFTs to total summer biomass of either zooplankton (A) or phytoplankton (B). The vertical separations indicate the different areas.
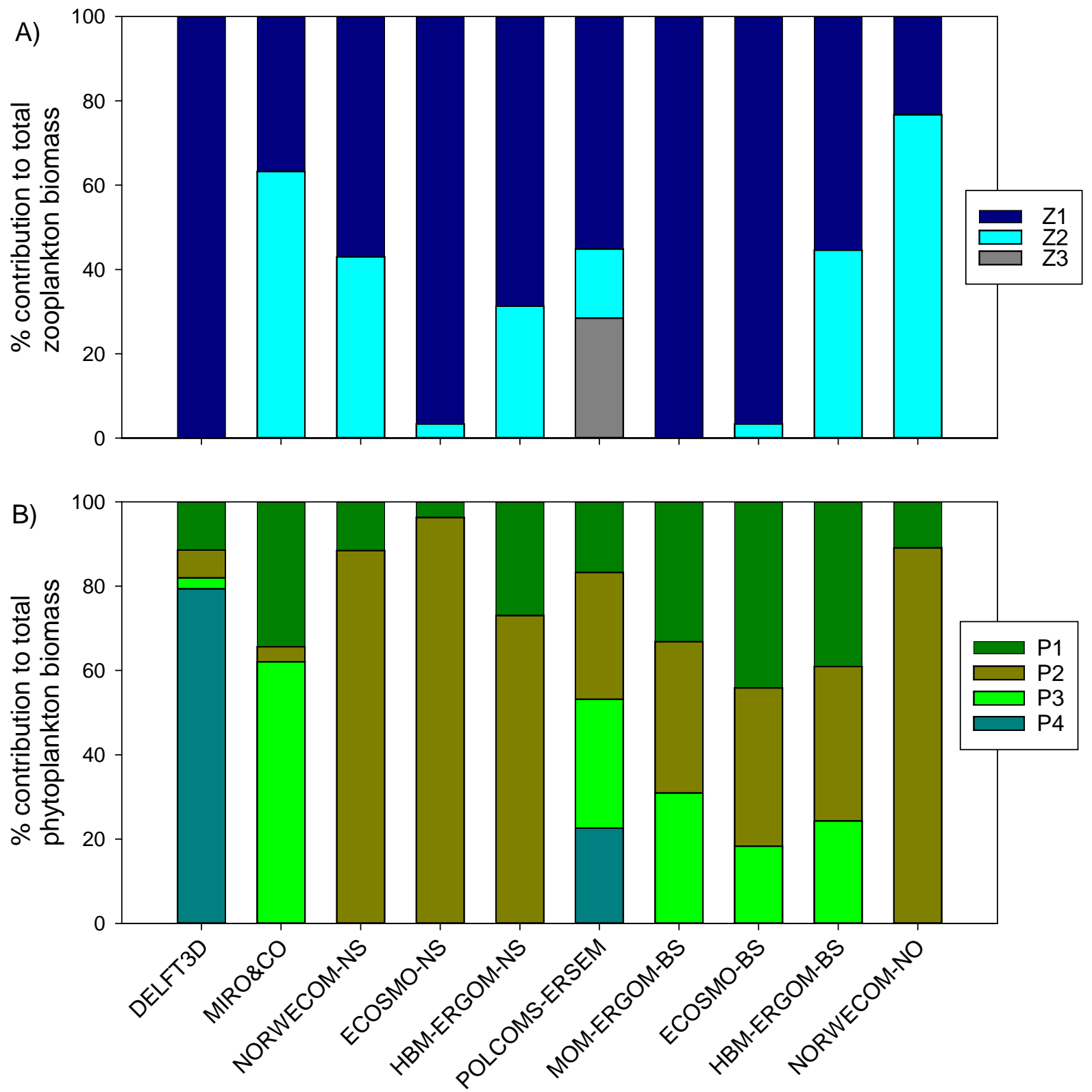
Figure 5. Spatial patterns of $\Delta C_{P H Y}$ (total summer phytoplankton biomass) in the North Sea models; A) DELFT3DGEM, B) MIRO\&CO, C) NORWECOM-NS, D) ECOSMO-NS), HBM-ERGOM-NS and POLCOMS-ERSEM for the scenarios P20 (left) and M20 (right). Please note the different scales.
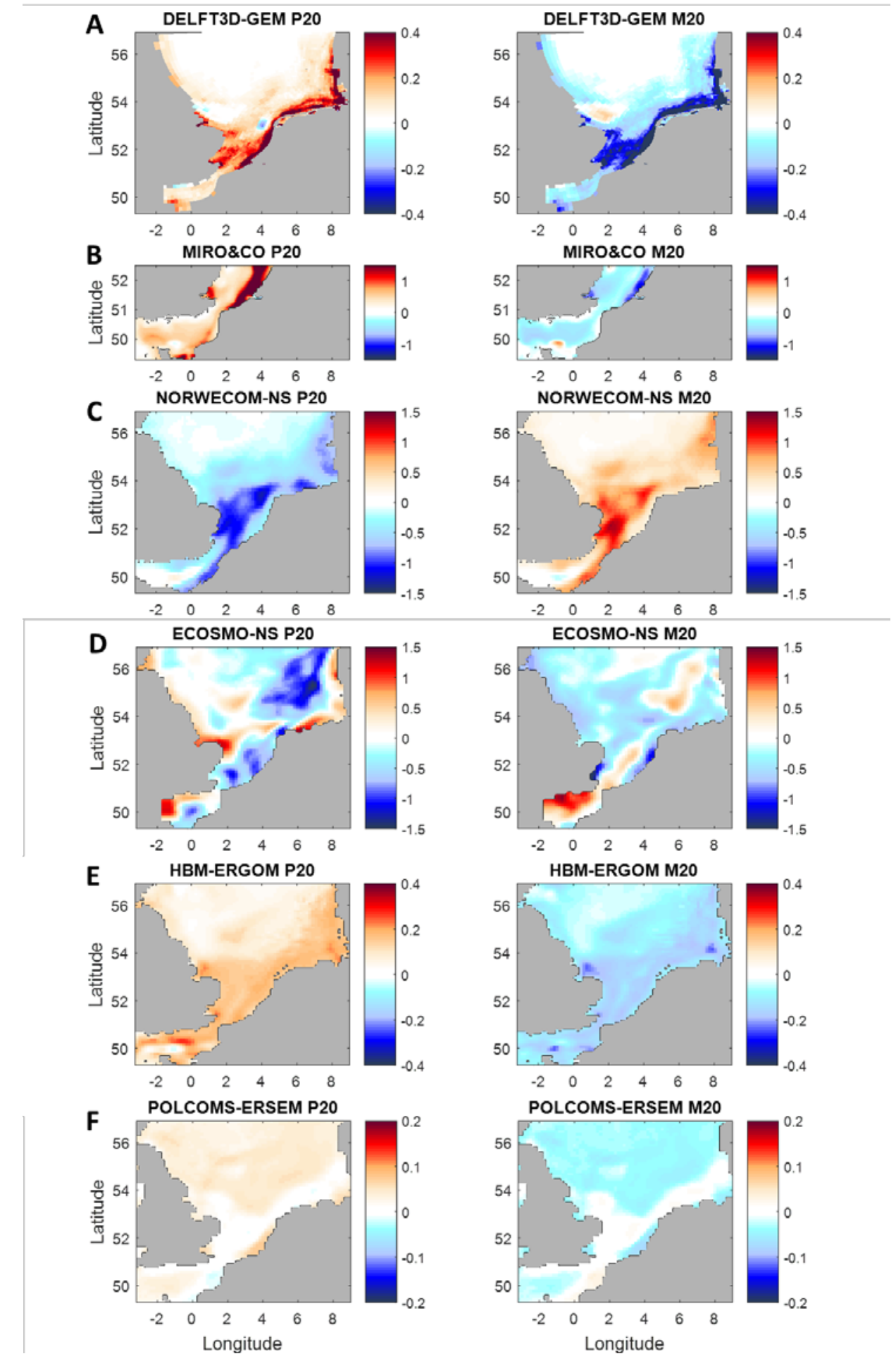
Figure 6. Spatial patterns of $\Delta C_{P H Y}$ (total summer phytoplankton biomass) in the Baltic Sea models; A) MOM-ERGOM, B) ECOSMO-BS, C) HBM-ERGOM-BS and the Nordic Seas D) NORWECOM-NO for the scenarios P20 (left) and M20 (right). Please note the different scales.
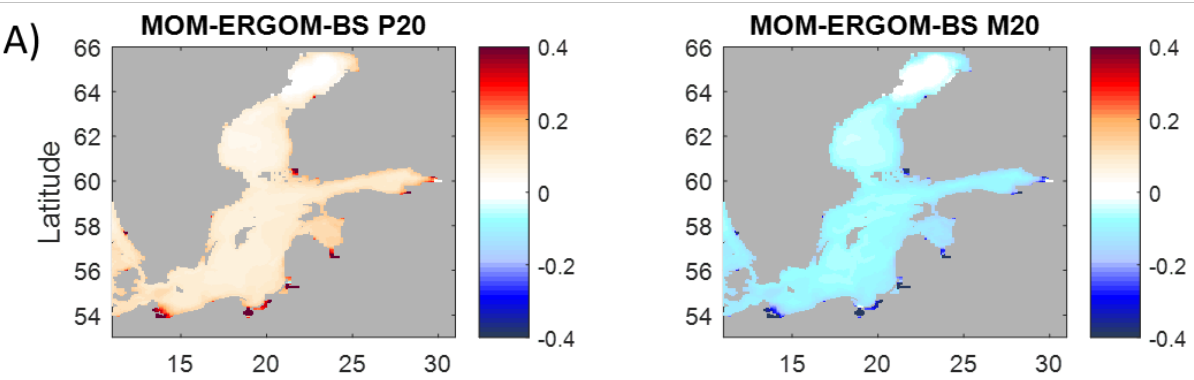

B)
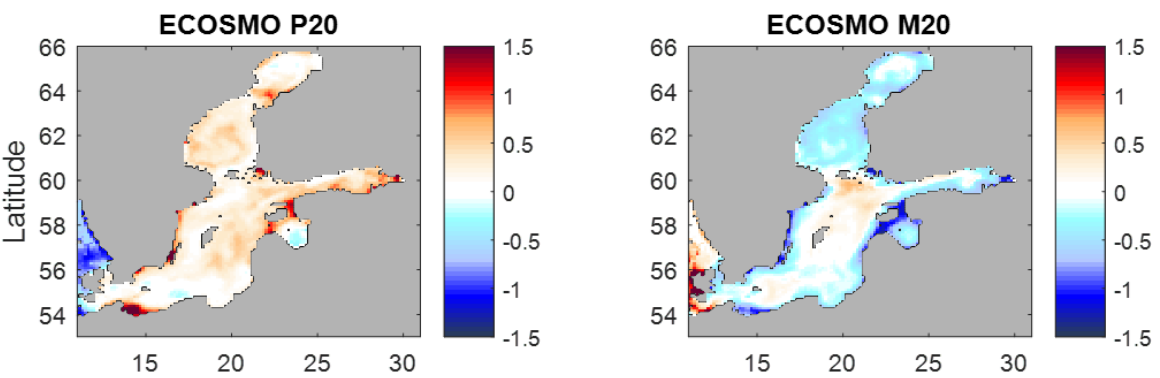

C)
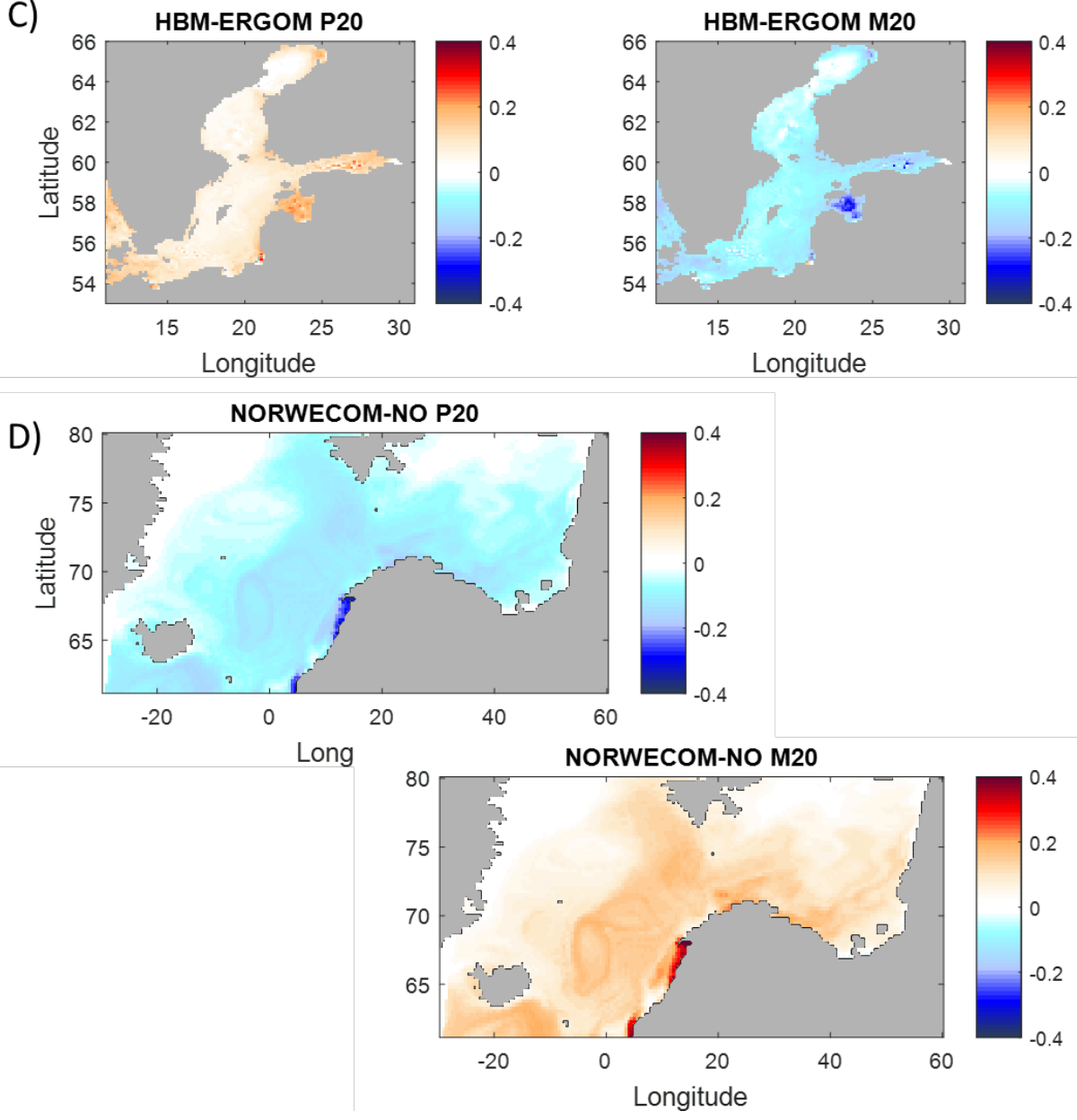